\title{
Structure and Reactivity of Supported Hybrid Platinum Nanoparticles for the Flow Hydrogenation of Functionalized Nitroaromatics
}

\author{
Gianvito Vilé, ${ }^{\dagger}$ Neyvis Almora-Barrios, ${ }^{\ddagger}$ Núria López, ${ }^{*}+\underset{\text { and Javier Pérez-Ramírez }}{ }{ }^{\dagger}{ }^{\dagger}$ \\ ${ }^{\dagger}$ Institute for Chemical and Bioengineering, Department of Chemistry and Applied Biosciences, ETH Zurich, Vladimir-Prelog-Weg 1, \\ 8093 Zurich, Switzerland \\ ${ }^{\ddagger}$ Institute of Chemical Research of Catalonia, ICIQ Av. Països Catalans 16, 43007 Tarragona, Spain
}

Supporting Information

ABSTRACT: This contribution targets the first comprehensive understanding of the next-generation catalyst for nitroarene hydrogenation, featuring ligand-capped $2 \mathrm{~nm}$ platinum nanoparticles (Pt-HHDMA, HHDMA: hexadecyl(2-hydroxyethyl)dimethylammonium dihydrogen phosphate) deposited on carbon. Fundamental questions related to the structure, properties, and mechanistic fingerprints of the metal-organic interphase of the hybrid system were addressed through a battery of advanced characterization methods and theoretical calculations. Catalytic tests conducted in a flow reactor at variable temperature and pressure revealed the superior activity of Pt-HHDMA in comparison with the archetypal and industrially relevant Lindlar-type $\mathrm{Pt}-\mathrm{Pb} / \mathrm{CaCO}_{3}$, with outstanding chemoselectivity and leaching resistance. The analysis of the reaction mechanism by Density Functional Theory, which was never addressed systematically, showed that the benefits of the ligand-modified catalyst arise from the facilitated $\mathrm{H}_{2}$ activation and weak nitroarene adsorption on the HHDMA-modified surface. At the same

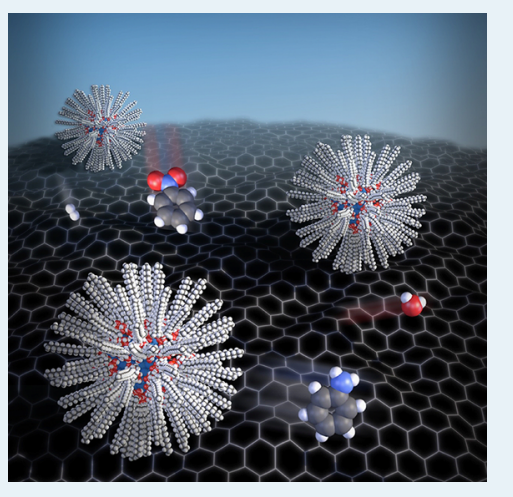
time, the ligand isolates the platinum ensemble, reducing the possibility of unselective routes by controlling the adsorption geometry and extent of the reactant and product intermediates. These results substantially enrich the mechanistic understanding of HHDMA-modified $\mathrm{Pt}$ catalyst and are of fundamental relevance for future improvements of this hybrid catalyst and for extrapolating this technology to other challenging reactions.

KEYWORDS: nitroarene hydrogenation, aromatic amines, ligand-stabilized nanoparticles, platinum, Lindlar catalyst, colloidal synthesis, flow chemistry, Density Functional Theory

\section{INTRODUCTION}

Highly dispersed metal nanoparticles supported on inorganic or organic carriers form the basis for many heterogeneous catalysts in the chemical industry. ${ }^{1}$ Due to remarkable achievements in the field of colloidal chemistry, ${ }^{2,3}$ the past decade has witnessed the development of new methods for synthesizing metal nanoparticles with tailored size and shape and controlled interaction with their surroundings. These factors, in fact, determine the selectivity of the materials when used as catalysts. ${ }^{4}$ The samples are typically prepared from a colloidal suspension of the metal salt, using inorganic reducing agents such as hydrazine or $\mathrm{LiBH}_{4}$, and organic ligands that limit metal aggregation, such as poly( $\mathrm{N}$-vinyl-2-pyrrolidone), N-heterocyclic carbene, or triphenylphosphine. ${ }^{5}$ Despite the growing number of publications in this area, the exploitation of colloidal methods at the industrial scale is often hampered by the use of expensive and toxic reagents and solvents. ${ }^{6}$ In an attempt to reduce the use of stoichiometric compounds, BASF has invented the NanoSelect technology, comprising surfactantstabilized $\mathrm{Pt}$, Pd, and $\mathrm{Pt}-\mathrm{Pd}$ nanocatalysts prepared in aqueous medium, using the nontoxic hexadecyl(2-hydroxyethyl)dimethylammonium dihydrogen phosphate (HHDMA) ionic liquid as a reducing and stabilized agent. ${ }^{6,7}$ These materials, which are marketed as lead-free alternatives to Lindlar-type catalysts, have been successfully applied in the selective hydrogenation of a variety of compounds. ${ }^{6,7}$

We have recently investigated the performance of NanoSelect-Pd in the continuous semihydrogenation of functionalized alkynes, deriving structure-performance relationships. ${ }^{8}$ Despite the 10-fold lower Pd content in the colloidal system, these materials match or even exceed the stereo- and chemoselectivity of the Lindlar-type $\mathrm{Pd}-\mathrm{Pb} / \mathrm{CaCO} \mathrm{C}_{3}$ catalyst. Notably, distinctions in the catalytic performance were correlated with the relative accessibility of the organic substrate to the active site, as well as with the adsorption configuration and strength, depending on the ensemble size and surface potentials. ${ }^{8}$ Nonetheless, relevant structural aspects including the preferential adsorption of the surfactant on planar or stepped surfaces of the metal and the extent of the HHDMA anchored to the support have not yet been addressed, although

\footnotetext{
Received: April 29, 2015

Revised: $\quad$ May 8, 2015

Published: May 11, 2015
} 
they would enable a more comprehensive understanding of the structure and reactivity of these materials.

The hydrogenation of functionalized nitroaromatics to aniline derivatives is relevant for the production of key building blocks in the synthesis of pharmaceuticals, polymers, herbicides, and dyestuffs. ${ }^{9,10}$ This type of reaction is currently conducted in (semi)batch slurry reactors, ${ }^{11}$ using Pt nanoparticles modified with the addition of lead, bismuth, phosphoric acid, or vanadium. ${ }^{12}$ Despite the good reactivity and significant degree of selectivity exhibited by these materials at mild reaction conditions, new restrictions in the use of harmful modifiers call for sustainable catalytic formulations. Besides, the advantage of a batch reactor is the versatility of the equipment, which is flexible to accommodate miscellaneous types of reactions during different industrial campaigns. However, it has been recently demonstrated that $50 \%$ of the reactions performed in the pharmaceutical and fine chemical industries (including the chemoselective hydrogenation of nitroaromatics) would benefit from a continuous operation, due to the improved mass and heat transfer and shorter reaction times, leading to a high spacetime yield, energy saving, and safety. ${ }^{13-15}$ The mechanism of nitroarene hydrogenation was proposed by Haber in the late 1890 s for the equivalent electrochemical reaction and entails two competing pathways (Scheme 1 ). ${ }^{16}$ In one case, it involves the reduction of the nitro to a nitroso group, the rapid addition of a second equivalent of hydrogen resulting in the formation of

Scheme 1. Haber Mechanism Describing the Hydrogenation of Nitrobenzene to Aniline, Showing the Direct Reduction (Blue) and the Condensation (Red) Routes ${ }^{a}$

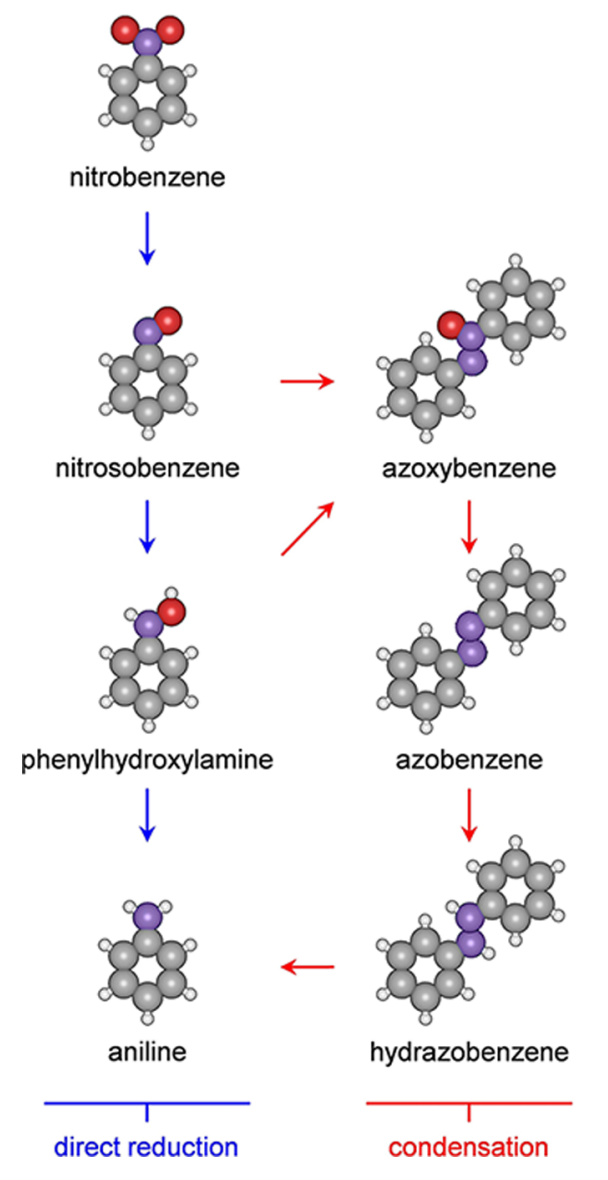

${ }^{a}$ Color codes: $\mathrm{H}$ (white), C (gray), N (purple), and O (red). hydroxylamine, and the production of aniline by hydrogenation of hydroxylamine. In the other case, two nitroaromatic intermediates interact leading to dimers (azo, azoxy, and hydrazo species). To the best of our knowledge, this mechanism was never corroborated on theoretical grounds and many hypotheses regarding the adsorption and reactivity of the reducible nitroaromatic on platinum require clarification. $^{10,17}$

In this work, we have studied the hydrogenation of functionalized nitroaromatics over the poison-free NanoSelect-Pt catalyst (Pt-HHDMA/C). The combination of advanced characterization methods, systematic kinetic tests in a three-phase continuous microreactor, Density Functional Theory (DFT), and classical and first-principles Molecular Dynamics (MD) enabled a better understanding of the structure of this hybrid catalyst and its superior catalytic performance with respect to the benchmark $\mathrm{Pt}-\mathrm{Pb} / \mathrm{CaCO}_{3}$ (Figure 1). Besides, we provide the first validation by DFT of the Haber mechanism for nitroarene hydrogenation.

\section{EXPERIMENTAL SECTION}

2.1. Catalysts. The ligand-modified Pt-HHDMA/C catalyst (0.8 wt \% Pt; NanoSelect Pt-100, Strem Chemicals, ref: 781630) was used as received. As detailed elsewhere, ${ }^{7}$ the catalyst was prepared by dissolving $\mathrm{H}_{2} \mathrm{PtCl}_{6}$ in an acidic solution containing water and HHDMA. A slurry of carbon powder in water was added to the mixture, and the suspension was stirred at $353 \mathrm{~K}$ for $2 \mathrm{~h}$. The catalyst was finally filtered off and extensively washed. The organic capping layer on the surface of the Pt nanoparticles could be eventually removed by applying an UV-ozone treatment, using a Bulbtronics $16 \mathrm{~W}$ low-pressure mercury lamp emitting at $185-257 \mathrm{~nm}$ and positioned at a distance of $5 \mathrm{~mm}$ from the sample. The Lindlar-type $\mathrm{Pt}-\mathrm{Pb}$ / $\mathrm{CaCO}_{3}$ (5 wt \% Pt +1 wt \% Pb) catalyst was prepared by following a published recipe. ${ }^{17}$ Briefly, potassium tetrachloroplatinate (0.17 g, Alfa Aesar, 99.999\%) was dissolved at room temperature in aqueous $\mathrm{HCl}\left(0.5 \mathrm{M}, 3 \mathrm{~cm}^{3}\right)$, followed by dropwise addition of aqueous $\mathrm{NaOH}(3 \mathrm{M})$, until reaching a $\mathrm{pH}$ of 4.5 . The calcium carbonate carrier (1.5 g, Fluka, >99.5\%) was added to the solution, and the resulting suspension was stirred for $30 \mathrm{~min}$ at $353 \mathrm{~K}$. Aqueous sodium formate $(0.7 \mathrm{M}, 1$ $\mathrm{cm}^{3}$, Fluka, >98\%) was supplied as reducing agent, and the brown slurry was magnetically stirred for $30 \mathrm{~min}$ until turning black, indicating the reduction of the platinum cations into $\mathrm{Pt}^{0}$. The solid was filtered off and extensively washed with deionized water. Afterward, the moist catalyst paste was poured into aqueous lead acetate trihydrate $\left(0.04 \mathrm{M}, 1 \mathrm{~cm}^{3}\right.$, ABCRChemicals, 99\%), and the slurry was stirred for $1 \mathrm{~h}$ at $353 \mathrm{~K}$. The solid was separated by filtration, washed with deionized water, and dried overnight at $338 \mathrm{~K}$.

2.2. Characterization Methods. The platinum and lead content was determined by inductively coupled plasma optical emission spectrometry (ICP-OES) using a Horiba Ultra 2 instrument equipped with a photomultiplier tube. The $\mathrm{H}, \mathrm{C}, \mathrm{N}$, $\mathrm{O}, \mathrm{P}$, and $\mathrm{Cl}$ content was determined by elemental analysis in a LECO CHN 900 combustion furnace. Scanning transmission electron microscopy (STEM) was undertaken in a FEI Tecnai F30 FEG operated at $300 \mathrm{kV}$. Secondary electron micrographs of the uncoated samples were acquired using a Zeiss Gemini 1530 FEG SEM operated at $1 \mathrm{kV}$. The materials were dispersed as dry powders on holey carbon-coated copper grids. Pulse chemisorption of carbon monoxide was conducted in a Thermo TPDRO 1100 analyzer. The sample $(50 \mathrm{mg})$ was pretreated in 

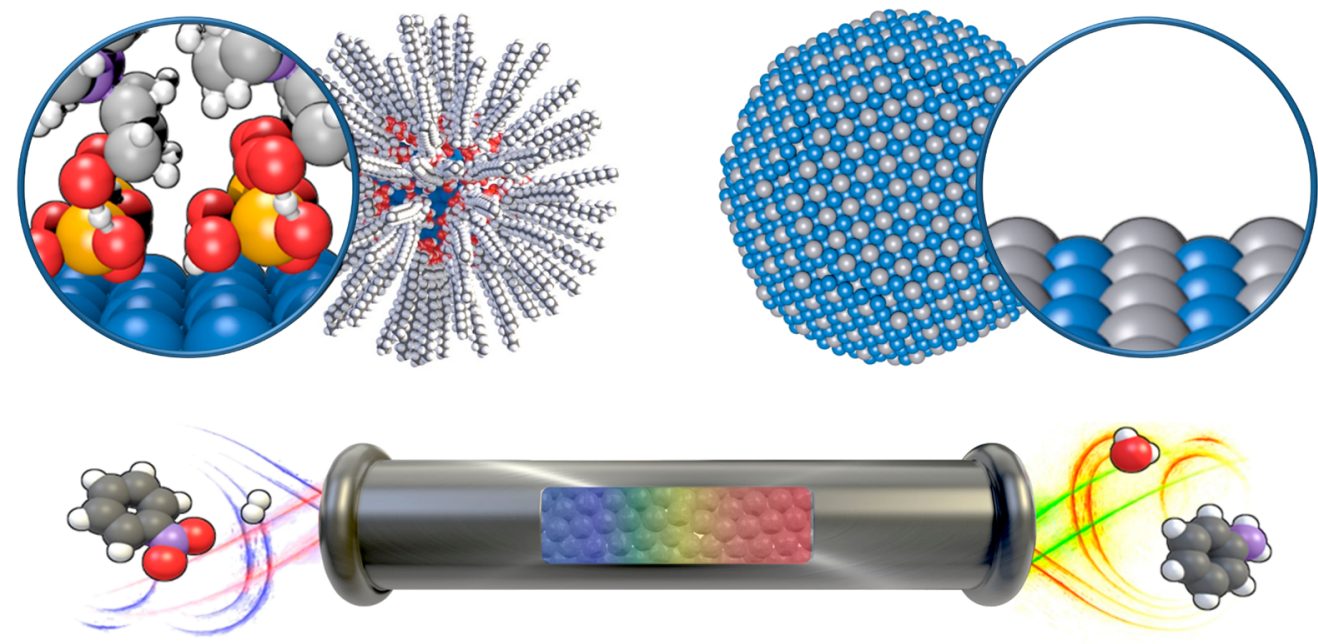

Figure 1. Illustration of the flow hydrogenation of a representative nitroaromatic compound (bottom) and structures of the Pt-HHDMA and $\mathrm{Pt}-\mathrm{Pb}$ nanoparticles with an inset on the metal surface (top). Color codes: $\mathrm{H}$ (white), C (light gray), $\mathrm{N}$ (purple), O (red), P (orange), $\mathrm{Pb}$ (dark gray), and Pt (dark blue).

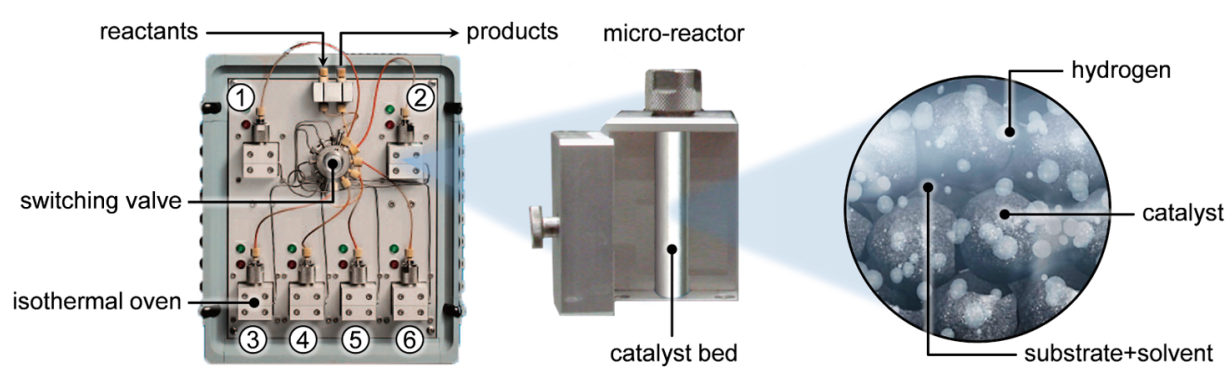

Figure 2. High-throughput flow chemistry technology consisting of six microreactors, enabling accelerated catalyst testing and quantitative kinetic studies of three-phase reactions in continuous operation. The picture on the right is a schematic representation of the catalyst particles during threephase hydrogenation and was created with the help of Blender, an open-source 3D computer graphics software.

$\mathrm{He}\left(20 \mathrm{~cm}^{3} \mathrm{~min}^{-1}\right)$ at $393 \mathrm{~K}$ for $1 \mathrm{~h}$ and reduced in $5 \mathrm{vol} \%$ $\mathrm{H}_{2} / \mathrm{He}\left(20 \mathrm{~cm}^{3} \mathrm{~min}^{-1}\right)$ at $348 \mathrm{~K}$ for $30 \mathrm{~min}$. Thereafter, 0.344 $\mathrm{cm}^{3}$ of $1 \mathrm{vol} \% \mathrm{CO} / \mathrm{He}$ was pulsed into the catalyst bed at 308 $\mathrm{K}$ every $4 \mathrm{~min}$. The platinum dispersion was calculated from the amount of chemisorbed $\mathrm{CO}$, considering an atomic surface density of $1.47 \times 10^{19}$ atoms $\mathrm{m}^{-2}$ and an adsorption stoichiometry of $\mathrm{Pt} / \mathrm{CO}=1 .^{18}$ Nitrogen isotherms were measured at $77 \mathrm{~K}$ in a Micromeritics 3Flex instrument after sample evacuation at $393 \mathrm{~K}$ for $6 \mathrm{~h}$. X-ray diffraction (XRD) was measured on a PANalytical X'Pert PRO-MPD diffractometer (see Section 1 in the Supporting Information). Data were recorded in the $10-70^{\circ} 2 \theta$ range with an angular step size of $0.02^{\circ}$ and a counting time of $0.26 \mathrm{~s}$ per step. X-ray photoelectron spectroscopy (XPS) was performed on a VG Microtech Multilab 3000 spectrometer featuring a hemispheric electron analyzer with 9 channeltrons and nonmonochromatized $\mathrm{Al} \mathrm{K} \alpha$ radiation at $1486.6 \mathrm{eV}$. The catalysts were pretreated in $\mathrm{He}\left(20 \mathrm{~cm}^{3} \mathrm{~min}^{-1}\right)$ at $393 \mathrm{~K}$ for $1 \mathrm{~h}$. The spectra were collected under ultrahigh vacuum conditions (residual pressure $\left.=5 \times 10^{-8} \mathrm{~Pa}\right)$ at a pass energy of $50 \mathrm{eV}$. In order to compensate for charging effects, all binding energies were referenced to the $\mathrm{C} 1 \mathrm{~s}$ level at $284.6 \mathrm{eV}$. Thermogravimetric analysis (TGA) was performed in a Mettler Toledo TGA/DSC 1 Star microbalance connected to a Pfeiffer Vacuum ThermoStar GSD $320 \mathrm{~T} 1$ mass spectrometer, after pretreatment of the samples in $\mathrm{N}_{2}\left(40 \mathrm{~cm}^{3} \mathrm{~min}^{-1}\right)$ at $393 \mathrm{~K}$ for $1 \mathrm{~h}$. The analysis was performed in air $\left(40 \mathrm{~cm}^{3} \mathrm{~min}^{-1}\right)$, ramping the temperature from 298 to 1173 at $10 \mathrm{~K} \mathrm{~min}^{-1}$. Fourier transform infrared
(FTIR) spectroscopy was performed in a Bruker Optics Vertex 70 spectrometer equipped with high temperature cell, $\mathrm{ZnSe}$ windows, and a mercury-cadmium-telluride detector. The cell was filled with powdered catalyst and carefully leveled to minimize reflection from the sample surface. The spectra were recorded in $\mathrm{He}\left(20 \mathrm{~cm}^{3} \mathrm{~min}^{-1}\right)$ at $473 \mathrm{~K}$. Time-of-Flight Secondary Ion Mass Spectrometry (ToF-SIMS) was performed on a ION-ToF GmbH ToF.SIMS.5 reflectron-based mass spectrometer equipped with $\mathrm{a} \mathrm{Bi}_{3}{ }^{+2}$ primary ion gun operated at $50 \mathrm{kV}$ and an electron flood gun for charge compensation. Prior to data collection, the reference HHDMA surfactant was diluted in ethanol and a few droplets of the solution were deposited on a silicon wafer and dried in ambient air for $2 \mathrm{~h}$. A thin layer of powdered catalyst was deposited on an aluminum foil. The analysis was conducted by recording the secondary ion mass spectra in the atomic mass unit range of $1-600$, using a probing area of $200 \times 200 \mu \mathrm{m}^{2}$. In the positive mass mode, the calibration of the mass spectra was based on $\mathrm{CH}_{3}{ }^{+}(\mathrm{m} / \mathrm{e}$ 15.025), $\mathrm{C}_{2} \mathrm{H}_{5}^{+}$(m/e 29.04), $\mathrm{C}_{3} \mathrm{H}_{7}^{+}$(m/e 43.05), and $\mathrm{C}_{4} \mathrm{H}_{9}{ }^{+}$ $(m / e$ 57.07). In the negative mass mode, the calibration was based on $\mathrm{CH}^{-}$(m/e 13.01), $\mathrm{C}_{2} \mathrm{H}^{-}\left(m / e\right.$ 25.01), $\mathrm{C}_{3} \mathrm{H}^{-}(m / e$ 37.01), and $\mathrm{C}_{4} \mathrm{H}^{-}(\mathrm{m} / \mathrm{e}$ 49.01). The normalized intensities were obtained by dividing each peak of the spectra by the total measured intensity. ${ }^{31} \mathrm{P}$ magic-angle spinning nuclear magnetic resonance (MAS NMR) spectra were recorded at a spinning speed of $10 \mathrm{kHz}$ on a Bruker AVANCE 700 NMR spectrometer equipped with a $4 \mathrm{~mm}$ probe head and $2.5 \mathrm{~mm}$ $\mathrm{ZrO}_{2}$ rotors at $104.3 \mathrm{MHz}$. 
Table 1. Composition, Porosity, and Metal Dispersion of the Catalysts

\begin{tabular}{|c|c|c|c|c|c|c|c|c|c|c|c|c|}
\hline catalyst & $\begin{array}{c}\mathrm{Pt}^{a} \\
\text { (wt \%) }\end{array}$ & $\begin{array}{c}\mathrm{Pb}^{a} \\
\text { (wt \%) }\end{array}$ & $\begin{array}{c}\mathrm{C}^{b} \\
(\mathrm{wt} \%)\end{array}$ & $\begin{array}{c}\mathrm{H}^{b} \\
\text { (wt \%) }\end{array}$ & $\begin{array}{c}\mathrm{O}^{b} \\
\text { (wt \%) }\end{array}$ & $\begin{array}{l}\mathrm{N}^{b} \\
(\mathrm{wt} \%)\end{array}$ & $\begin{array}{c}\mathrm{P}^{b} \\
(\text { wt } \%)\end{array}$ & $\mathrm{Cl}^{b}$ (wt \%) & $\begin{array}{c}S_{\mathrm{BET}}^{c} \\
\left(\mathrm{~m}^{2} \mathrm{~g}^{-1}\right)\end{array}$ & $\begin{array}{c}V_{\text {pore }}^{d} \\
\left(\mathrm{~cm}^{3} \mathrm{~g}^{-1}\right)\end{array}$ & $\begin{array}{l}D_{\mathrm{CO}}^{e} \\
(\%)\end{array}$ & $\begin{array}{c}D_{\text {TEM }}^{f} \\
(\%)\end{array}$ \\
\hline Pt-HHDMA/C & 0.8 & 0.0 & 88.9 & 2.6 & 6.3 & 0.7 & 0.2 & $0.5(0.02)^{g}$ & 234 & 0.32 & 47 & 49 \\
\hline $\mathrm{Pt}-\mathrm{Pb} / \mathrm{CaCO}_{3}$ & 5.1 & 1.0 & - & 0.0 & 0.0 & 0.0 & 0.0 & 0.0 & 4 & 0.01 & 7 & 8 \\
\hline
\end{tabular}

2.3. Catalytic Evaluation. The hydrogenation of nitroaromatic compounds was carried out in the fully automated ThalesNano H-Cube Pro setup. As described elsewhere, ${ }^{8}$ the system is equipped with an electrolytic cell for in situ $\mathrm{H}_{2}$ generation using Millipore water, an HPLC pump for the feeding of the reactants, an autosampler, and a CatChanger. The latter, in particular, consists of six parallel isothermal microreactors (Figure 2), which enable high-throughput data acquisition and fast kinetic studies. The gaseous hydrogen and the liquid mixture containing both the nitroaromatic substrate and the solvent flow concurrently upward through a stainlesssteel cartridge of ca. $3.5 \mathrm{~mm}$ internal diameter placed into the CatChanger. This contains a fixed bed of particles, comprising the catalyst $(0.1 \mathrm{~g})$ and silica (ca. $0.07 \mathrm{~g})$, both with a particle size of $0.2-0.4 \mathrm{~mm}$. This configuration is referred to as "flooded-bed reactor" and, compared to the standard downflow "trickle-bed reactor", is particularly advantageous for studying three-phase hydrogenation reactions due to the much higher mass and heat transfer coefficients between the gas and the liquid phases. ${ }^{19}$ The nitroaromatic substrates included nitrobenzene (Sigma-Aldrich, 99\%), 1-chloro-4-nitrobenzene (Sigma-Aldrich, 99\%), 4-nitrostyrene (TCI Deutschland $\mathrm{GmbH}, 95 \%)$, 4-nitrotoluene (Sigma-Aldrich, 99\%), 1,4dinitrobenzene (Alfa-Aesar, >98\%), 5-methyl-2-nitroaniline (Sigma-Aldrich, 95\%), and 4-nitrobenzamide (ABCR-Chemicals, 98\%). Unless specified otherwise, the inlet solutions contained 5 vol \% of the nitroaromatic substrate and tetrahydrofuran (THF, Sigma-Aldrich, 99.9\%) as the solvent. The kinetic tests were performed at various temperatures $(303-363 \mathrm{~K})$, pressures $(1-60 \mathrm{bar})$, and liquid $\left(0.3-3 \mathrm{~cm}^{3}\right.$ $\mathrm{min}^{-1}$ ) and $\mathrm{H}_{2}\left(3-60 \mathrm{~cm}^{3} \mathrm{~min}^{-1}\right)$ flow rates. The reaction products were collected after reaching (in only $10 \mathrm{~min}$ ) steadystate operation, and analyzed offline in a HP-6890 gas chromatograph equipped with a HP-5 capillary column and a flame ionization detector. The conversion of the nitroaromatic compound $\left(X_{\mathrm{NA}}\right)$ and the selectivity to product $i\left(S_{i}\right)$ were calculated as

$$
\begin{aligned}
& X_{\mathrm{NA}}(\%)=100 \times\left(c_{\mathrm{in}, \mathrm{NA}}-c_{\mathrm{out}, \mathrm{NA}}\right) / c_{\mathrm{in}, \mathrm{NA}} \\
& S_{i}(\%)=100 \times\left(c_{\mathrm{out}, i}\right) /\left(c_{\mathrm{in}, \mathrm{NA}}-c_{\mathrm{out}, \mathrm{NA}}\right)
\end{aligned}
$$

where $c_{\mathrm{in}, \mathrm{NA}}$ and $c_{\mathrm{out}, \mathrm{NA}}$ are, respectively, the inlet and outlet concentration of the target nitroaromatic compound, and $c_{\text {out }, i}$ is the outlet concentration of the product $i$.

\section{COMPUTATIONAL DETAILS}

Periodic DFT calculations were performed with the VASP code, ${ }^{20,21}$ using the generalized gradient approximation (GGA) in the form of the revised Perdew-Burke-Ernzerhof $(\mathrm{RPBE})^{22}$ exchange-correlation functional. In order to include the dispersion contributions in the functional, the DFT-D2 approach was used, ${ }^{23,24}$ employing for $\mathrm{Pt}$ and $\mathrm{Pb}$ the parameters refined in our previous work. ${ }^{25}$ The projected augmented wave (PAW) method was used to describe the interaction between valence and core electrons. ${ }^{26}$ The number of plane waves was determined by a kinetic cutoff energy of 450 $\mathrm{eV}$ and the number of $k$-points was adapted to achieve a similar sampling density in the reciprocal space. The structure of HHDMA was reoptimized on the basis of the previous work on supported Pd-HHDMA. ${ }^{8}$ This ligand features a quaternary ammonium polar group attached to an aliphatic chain that interacts with the dihydrogen phosphate anion by electrostatic forces; on the other hand, the hydrocarbon tail is able to selforganize linearly by van der Waals interactions.

To model the Pt-HHDMA catalyst, we have considered lowindex $\operatorname{Pt}(111)$ and $\operatorname{Pt}(311)$ faces containing surface platinum atoms with coordination numbers of 9 and 6, respectively. In particular, we have performed supercell $p(2 \times 2)$ periodic calculations of slabs with thicknesses of five atomic layers and vacuum gap of ca. $20 \AA$. The two atomic layers at the top were allowed to relax, whereas the three bottom layers were fixed at their bulk positions. We have adsorbed one HHDMA molecule per surface simulation cell; the energy of adsorption on the $\mathrm{Pt}$ surfaces was calculated as $E_{\text {ads }}=E_{\text {surf }+ \text { HHDMA }}-E_{\text {surf }}-E_{\text {HHDMA }}$ where $E_{\text {surf }+ \text { HHDMA }}$ is the energy of the surface with the adsorbed HHDMA species, $E_{\text {surf }}$ is the energy of the simulation cell containing only the surface, and $E_{\mathrm{HHDMA}}$ is the energy of the HHDMA crystal structure per formula unit. It has been recently proposed that the interface between $\mathrm{Pt}$ and the surfactant might contain residual chlorine anions from the preparation process. $^{27}$ We have analyzed the possible interaction of these ions with HHDMA and Pt, and the results of the calculation are included in the Supporting Information (Section 2). To model the Pt-Lindlar catalyst, single platinum atoms in the first layer of $\mathrm{Pt}(111)$ were substituted with lead with a $0.25 \mathrm{ML}$ coverage, similarly to the Pd-Lindlar structure. $^{28,29}$ Notice that Lindlar-type Pt-Pb catalysts have been prepared in the past using different supports (i.e., carbonates, sulfates, and oxides). ${ }^{17}$ However, no effect on the activity and selectivity was noted. Besides, the average diameter of the $\mathrm{Pt}-\mathrm{Pb}$ nanoparticles in this system is approximately 8 $\mathrm{nm}$. If the sites at the interface between the metal particles and the support were relevant for the reaction, smaller nanoparticles would be more active. The fact that this is not experimentally encountered indirectly discards any role played by the support in the reaction, justifying the fact that we neglected to model the $\mathrm{CaCO}_{3}$ carrier.

The propensity of the catalysts to hydrogenate nitroaromatic compounds was assessed by considering the adsorption energy of specific reactants and products (specifically, $\mathrm{C}_{6} \mathrm{H}_{5} \mathrm{NO}_{2}$, $\mathrm{C}_{6} \mathrm{H}_{5} \mathrm{NH}_{2}, \mathrm{ClC}_{6} \mathrm{H}_{4} \mathrm{NO}_{2}$, and $\left.\mathrm{ClC}_{6} \mathrm{H}_{4} \mathrm{NH}_{2}\right)$ on a $p(4 \times 4)$ supercell. The climbing image nudged elastic band (CI-NEB) algorithm $^{30}$ was employed to calculate the transition states of the elementary steps involved in the hydrogenation of $\mathrm{ClC}_{6} \mathrm{H}_{4} \mathrm{NO}_{2}$ on $\mathrm{Pt}-\mathrm{Pb}$ and $\mathrm{Pt}-\mathrm{HHDMA}$, using at least four images along the reaction coordinate. The transition states were confirmed by having only one imaginary frequency.

Additional calculations to assess the convergence of adsorption energies of the reactants were performed on a nanoparticle with a diameter of $1.7 \mathrm{~nm}$ and capped with 
(a)

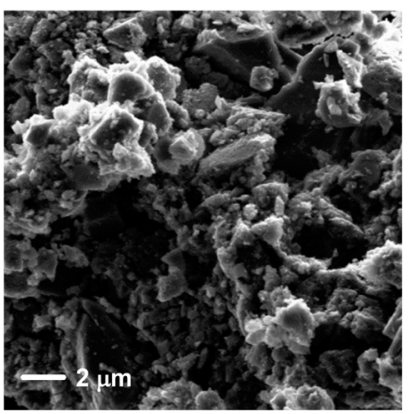

(b)

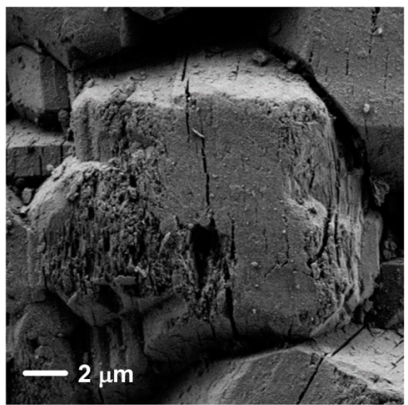

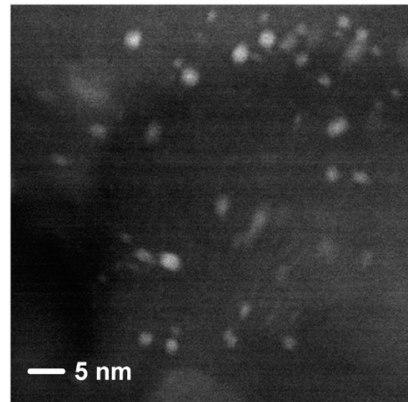
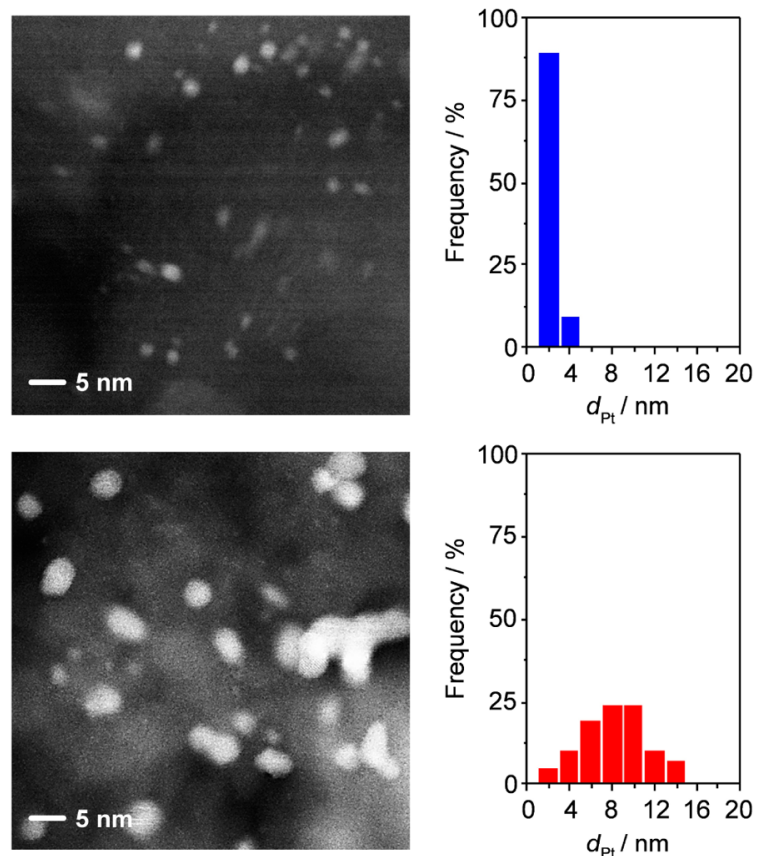

Figure 3. SEM (left) and HAADF-STEM (middle) micrographs, and respective particle size distributions (right) of Pt-HHDMA/C (a) and Pt-Pb/ $\mathrm{CaCO}_{3}(\mathrm{~b})$.

$\mathrm{H}_{2} \mathrm{PO}_{4}^{-}$and $\mathrm{N}^{+}\left(\mathrm{CH}_{3}\right)_{3}\left(\mathrm{CH}_{2}\right) \mathrm{OH}$. A 260-atom Pt nanoparticle was built in a cuboctahedron with a number of HHDMA molecules in agreement with the experiments. This structure was equilibrated through first-principles Molecular Dynamics (for a more detailed discussion, see Section 3 in the Supporting Information). The test shows that convergence was achieved and thus due to the large computational effort that the $1.7 \mathrm{~nm}$ nanoparticle implies we have employed the slab model instead.

\section{RESULTS AND DISCUSSION}

4.1. Catalyst Characterization. Main Differences between $\mathrm{Pt}-\mathrm{Pb}$ and Pt-HHDMA. The Pt-HHDMA/C catalyst contains 0.8 wt $\% \mathrm{Pt}$. Comparatively, $\mathrm{Pt}-\mathrm{Pb} / \mathrm{CaCO} \mathrm{C}_{3}$ has approximately 5 wt \% Pt and, in addition, 1 wt \% Pb (Table 1). Transmission electron microscopy confirms that the spherical Pt-HHDMA nanoparticles are well distributed over the carbon carrier of the hybrid catalyst (Figure 3), displaying an average diameter of ca. $2 \mathrm{~nm}$, which corresponds to a degree of metal dispersion of $49 \%$. However, the degree of $\mathrm{Pt}$ dispersion calculated from the micrographs (49\%, Table 1) is slightly higher than that determined by $\mathrm{CO}$ chemisorption (47\%), indicating that some of the platinum atoms over Pt-HHDMA/ $\mathrm{C}$ are inaccessible. The $\mathrm{Pt}-\mathrm{Pb}$ particles decorating the carbonate phase of the Lindlar-type catalyst exhibit a much broader size distribution centered at around $8 \mathrm{~nm}$ (Figure 3). This corresponds to a degree of metal dispersion of $7 \%$, in line with the results from $\mathrm{CO}$ chemisorption (Table 1), suggesting that all surface atoms are accessible to the reactants. XRD (Figure S1) further verifies the presence of typical Pt reflections in the case of $\mathrm{Pt}-\mathrm{Pb} / \mathrm{CaCO}_{3}$.

The total surface area of the hybrid Pt-HHDMA material is relatively high $\left(S_{\mathrm{BET}}=234 \mathrm{~m}^{2} \mathrm{~g}^{-1}\right)$ and the porous nature of the support $\left(V_{\text {pore }}=0.32 \mathrm{~cm}^{3} \mathrm{~g}^{-1}\right)$ is confirmed by scanning electron microscopy (Figure 3 ). The $\mathrm{Pb}$-poisoned material, in contrast, has a total surface area of only $4 \mathrm{~m}^{2} \mathrm{~g}^{-1}$ and a pore volume of $0.01 \mathrm{~cm}^{3} \mathrm{~g}^{-1}$; this is expected considering that the basic $\mathrm{CaCO}_{3}$ support is composed of large, nonporous particles
$\left(V_{\text {pore, } \mathrm{CaCO} 3}=0.03 \mathrm{~cm}^{3} \mathrm{~g}^{-1}\right)$. XPS (Figure 4) evidence a single Pt $4 \mathrm{f}_{7 / 2}$ core level peak at $71.9-72.0 \mathrm{eV}$ for Pt-HHDMA/C,

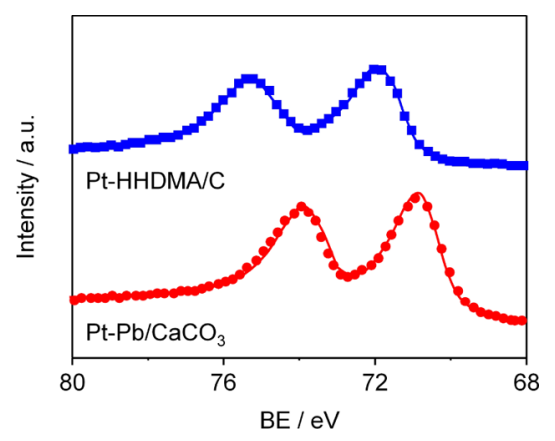

Figure 4. Pt 4f core level XPS spectra of the catalysts.

which is shifted ca. $0.9 \mathrm{eV}$ with respect to the peak corresponding to a $\mathrm{Pt}$ single crystal. ${ }^{31}$ This peak has been assigned in the past to $\mathrm{Pt}^{0}$ and attributed to quantum effects observed over extremely small $(\leq 2 \mathrm{~nm})$ Pt nanoparticles. ${ }^{32}$ However, we cannot exclude a minor contribution of oxidic $\mathrm{Pt}$ species. ${ }^{33}$ The XPS analysis of the $\mathrm{Pt}-\mathrm{Pb}$ catalyst, on the other hand, shows broad peaks with characteristic shoulders, in agreement with the literature, ${ }^{10,17}$ which are assigned to $\mathrm{Pt}^{0}$ and $\mathrm{Pt}^{2+}$ species. The atomic surface $\mathrm{Pt} / \mathrm{Pb}$ ratio, also determined by XPS, is ca. 2.5 .

Structure of Pt-HHDMA. Thermogravimetric analysis confirms the presence of HHDMA molecules adsorbed on the surface of the colloidally prepared $\mathrm{Pt}$ catalyst (Figure 5). The profile exhibits a first weight loss at 570-580 K, assigned to the decomposition of the ligand, and a second weight loss at ca. $800 \mathrm{~K}$, associated with the oxidation of the carbon support. At the high temperatures where the organic ligand decomposes, the $\mathrm{Pt}$ nanoparticles are expected to agglomerate. ${ }^{8}$ Thus, only the simultaneous action of ozone and ultraviolet light, which oxidize the carbon-containing ligand into carbon dioxide and 


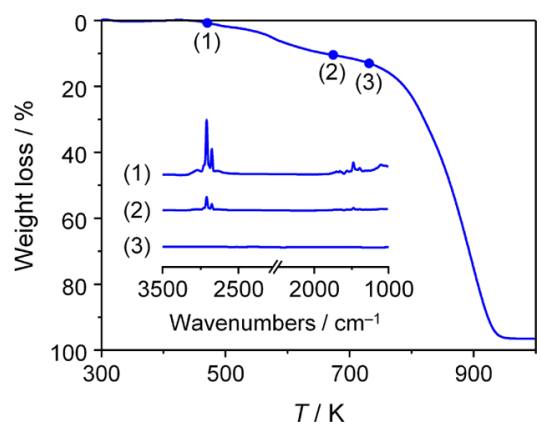

Figure 5. TGA profile in air of Pt-HHDMA/C. In the inset, DRIFT spectra at different temperatures $(1-3)$ of the same catalyst.

water, can selectively remove the HHDMA shell without altering the Pt particle size. ${ }^{8}$ The presence of HHDMA on the $\mathrm{Pt}$ surface is further confirmed by the observation of characteristic bands between 3000 and $2800 \mathrm{~cm}^{-1}$ and between 1100 and $1200 \mathrm{~cm}^{-1}$ in the infrared spectra of the Pt-HHDMA sample (inset in Figure 5 and Table S1). The formers are assigned to the $\mathrm{C}-\mathrm{H}$ stretching vibration of the organic tail of the surfactant, while the latters are due to the phosphate group of HHDMA. ${ }^{34}$ The intensity of these bands starts to decrease at ca. $550 \mathrm{~K}$, in line with the TGA analysis.

The total content of $\mathrm{H}, \mathrm{C}, \mathrm{N}, \mathrm{O}, \mathrm{P}$, and $\mathrm{Cl}$ determined by elemental analysis are ca. 2.6, 88.9, 0.7, 6.3, 0.2, and $0.5 \mathrm{wt} \%$, respectively (Table 1 ). XPS, however, suggests that the $\mathrm{Cl}$ species are almost absent from the surface (surface concentration of $\mathrm{Cl}=0.02$ wt \%), in line with published works. ${ }^{27,35}$ The content of $\mathrm{C}$ cannot be taken into account for an accurate estimation of the quantity of HHDMA on the material, considering that the catalyst contains activated carbon as carrier. Contrarily, based on the content of $\mathrm{P}$ and considering the HHDMA stoichiometry $\left(\mathrm{C}_{20} \mathrm{H}_{44} \mathrm{NO}_{5} \mathrm{P}\right)$, we can approximately estimate the number of HHDMA molecules containing a phosphate group $\left(3 \times 10^{21}\right)$, which is 1 order of magnitude lower than that determined by considering the results for $\mathrm{H}, \mathrm{N}$, and $\mathrm{O}\left(3 \times 10^{22}\right)$. This discrepancy can be explained by taking into consideration that the surfactant adsorbs on both the $\mathrm{Pt}$ nanoparticles and the carbon support. In the former, the adsorption features a phosphate group connected with an $\mathrm{N}$ containing organic tail; in the latter, the adsorption occurs at the interphase between the N-containing tail of HHDMA and the hydroxyl groups on the support, with the orthophosphate anion being eliminated as $\mathrm{H}_{3} \mathrm{PO}_{4}{ }^{42}$ Thus, measuring the content of $\mathrm{P}$ appears to be the most accurate way to estimate the amount of ligand directly on the Pt nanoparticles. From the ratio between the concentration of HHDMA on Pt and that on the catalyst, it is possible to estimate that approximately $10 \%$ of the total HHDMA is deposited on the nanoparticles, and the remaining $90 \%$ is on the carrier. Notably, the concentration of organics does not change upon hydrogenation, pointing to the absence of HHDMA leaching.

In an attempt to understand the coordination of the ligand on the surface of $\mathrm{Pt}$, we have conducted ToF-SIMS analyses. This very sensitive surface technique, in fact, can be employed to examine the chemistry of strongly adsorbed molecules on catalysts. $^{36}$ The SIMS spectrum obtained for Pt-HHDMA/C (Figure 6a) after reference subtraction evidence a series of cluster ions at 210 and $246 \mathrm{~m} / \mathrm{e}$, assigned to $\mathrm{PtO}^{-}$and $\mathrm{PtOP}^{-}$, respectively, indicating direct interaction of the anionic phosphate head with the metal surface. NMR (Figure 6b),
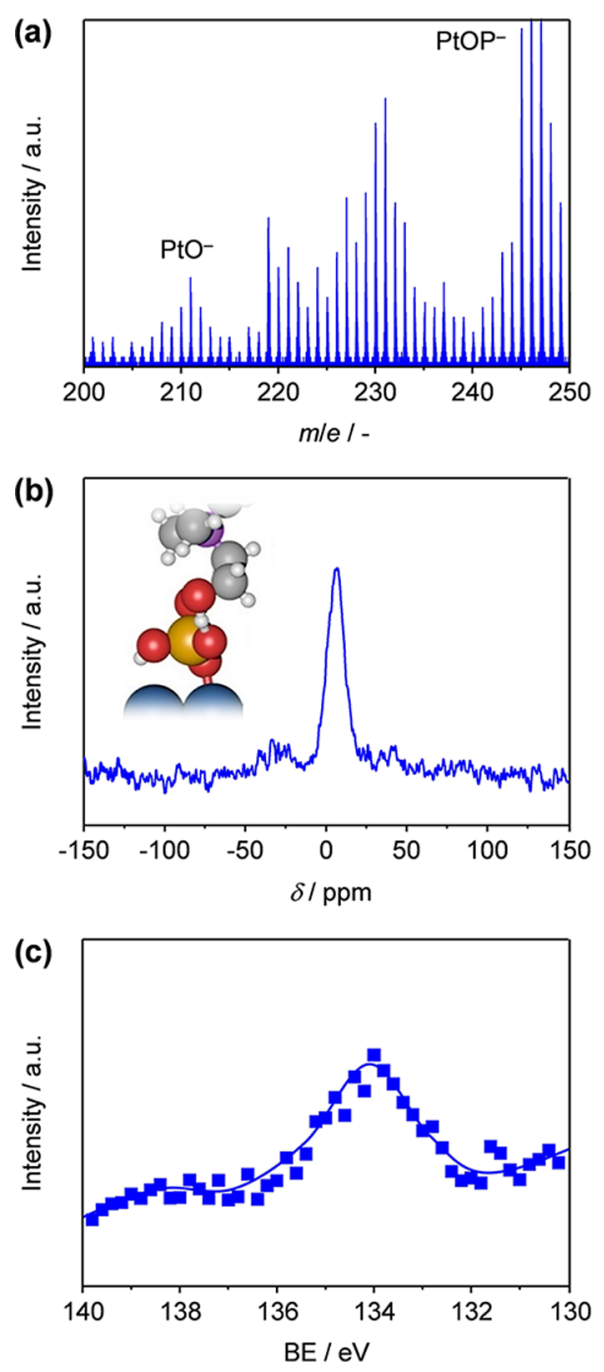

Figure 6. ToF SIMS (a), ${ }^{31} \mathrm{P}$ MAS NMR (b), and P $2 \mathrm{p}$ core level XPS (c) of Pt-HHDMA/C. The inset in (b) highlights the interaction of the ligand with the Pt surface via an orthophosphate group. Color codes as specified in the caption of Figure 1

which has been employed in the past to determine the structure of organic materials, including ligand molecules on nanoparticles, ${ }^{37}$ confirms a single chemical shift for the anion part belonging to an orthophosphate group. XPS (Figure 6c) further verifies the presence of a $\mathrm{P} 2 \mathrm{p}_{3 / 2}$ core level peak at $134 \mathrm{eV}$, attributed to $\mathrm{PO}_{4}{ }^{3-}$, proving that only the anionic part of the ligand interact with the platinum surface through an oxygen atom.

Dispersion-corrected DFT calculations not only confirm the experimental results but also provide new insights on the structure and energy landscape of the hybrid nanomaterial. The most favorable adsorption mode of HHDMA on the lowest energy surface, $\mathrm{Pt}(111)$, is through the oxygen atoms of the dihydrogen phosphate anion (Tables S2 and S3 and Figure S2a), in agreement with the preferential adsorption of anionic species. ${ }^{38}$ The quaternary ammonium head comprising the HHDMA tail remains in close proximity of the $\mathrm{H}_{2} \mathrm{PO}_{4}{ }^{-}$anion, interacting through electrostatic forces and an hydrogen bond between the $\mathrm{CH}_{2} \mathrm{OH}$ side tail and the $\mathrm{H}_{2} \mathrm{PO}_{4}{ }^{-}$group. This process is highly favorable, considering that the interaction energy of $\mathrm{Pt}(111)$-HHDMA with respect to the surfactant crystal reference is exothermic by $3.90 \mathrm{eV}$. Despite the presence 

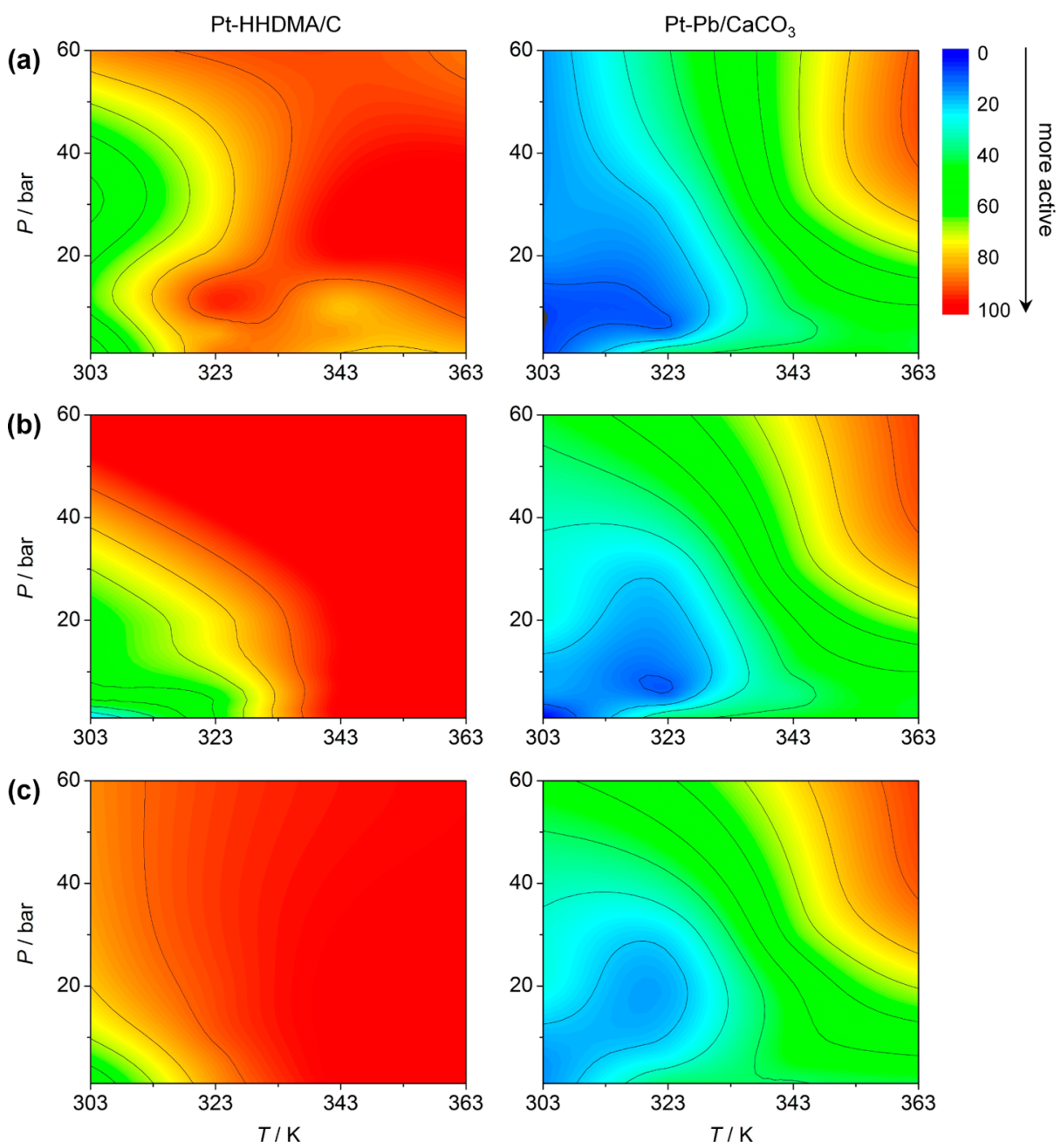

Figure 7. Conversion at different temperatures and pressures during the hydrogenation of nitrobenzene (a), chloronitrobenzene (b), and nitrostyrene (c) over Pt-HHDMA/C and Pt- $\mathrm{Pb} / \mathrm{CaCO}_{3}$. Conditions: $\mathrm{F}_{\mathrm{G}}\left(\mathrm{H}_{2}\right)=18 \mathrm{~cm}^{3} \mathrm{~min}^{-1}, F_{\mathrm{L}}$ (nitroarene $\left.+\mathrm{THF}\right)=3 \mathrm{~cm}^{3} \mathrm{~min}^{-1}$. The contour maps were created by spline interpolation of 25 experimental points. At all conditions, both catalysts are fully selective to the aniline products.

of low-coordination sites on the surface of a $2 \mathrm{~nm} \mathrm{Pt}$ nanoparticle, the stabilization gained at these faces is quite similar, suggesting that $\mathrm{Pt}(111)$ provides a reasonable representation of a typical active surface. In fact, the computed adsorption energy over $\mathrm{Pt}(311)$ is only $0.28 \mathrm{eV}$ more stable than that over $\mathrm{Pt}(111)$ and the main difference between both surfaces relates to the distance between the metal and oxygen atoms. On $\mathrm{Pt}(311)$, the ligand prefers to adsorb at the step position of the surface and two oxygen atoms coordinate with the Pt surface at around $2.11 \AA$ (Figure S2b). On Pt(111), the average distance is $2.77 \AA$ and three oxygen atoms interact with the surface. Besides, the distance between the cationic head of the tail and the surface is $7.17 \AA$ over $\operatorname{Pt}(311)$ and $7.77 \AA$ over $\operatorname{Pt}(111)$.

We have finally investigated which type of anion is more likely to be present at the interface of the hybrid catalyst, taking into account the presence of residual $\mathrm{Cl}^{-}$species (Tables S2 and S3, Figures S2c and S3). The models suggest that the $\mathrm{H}_{2} \mathrm{PO}_{4}{ }^{-}$anion can thermodynamically displace $\mathrm{Cl}^{-}$from the surface. The energy difference between both structures, obtained with respect to the surfactant crystal references, is $0.86 \mathrm{eV}$ in favor of the $\mathrm{H}_{2} \mathrm{PO}_{4}{ }^{-}$anion (for a more detailed discussion, see Section 2 in the Supporting Information).
4.2. Catalytic Performance. The contour maps in Figure 7 depict the activity of $\mathrm{Pt}-\mathrm{HHDMA} / \mathrm{C}$ and $\mathrm{Pt}-\mathrm{Pb} / \mathrm{CaCO}_{3}$ at different temperatures and pressures, in the continuous-flow three-phase hydrogenation of nitrobenzene, chloronitrobenzene, and nitrostyrene. At the conditions investigated, the conversion of nitrobenzene (Figure 7a) ranges between 20 and $100 \%$ over Pt-HHDMA/C and between 10 and 100\% over Pt$\mathrm{Pb} / \mathrm{CaCO}_{3}$. The former catalyst, in particular, appears to be more active, reaching full nitrobenzene conversion at much lower operating conditions ( $323 \mathrm{~K}$ and $10 \mathrm{bar}$ ) compared to $\mathrm{Pt}-\mathrm{Pb}$ ( $363 \mathrm{~K}$ and $40 \mathrm{bar}$ ). To compare the selectivity of the catalyst to the aniline product, the nitrobenzene conversion was fixed at $40 \%$ by changing the temperature (Table 2). In fact, longer contact time can adjust the conversion of the nitro compound. However, due to the limitations of the liquid and gas dosing systems in our reactor setup, we are not able to attain contact times lower than $0.1 \mathrm{~s}$. For this reason, the data in Table 2 are collected at $303 \mathrm{~K}$ over Pt-HHDMA and at 363 $\mathrm{K}$ over $\mathrm{Pt}-\mathrm{Pb}$. This comparison, however, is meaningful, considering that the samples are fully selective at all temperatures and pressures investigated (see the caption of Figure 7). In particular, the aniline selectivity is $100 \%$ over PtHHDMA and $98 \%$ over $\mathrm{Pt}-\mathrm{Pb}$ (Table 2). Hydroxylamine is the only byproduct over $\mathrm{Pt}-\mathrm{Pb} / \mathrm{CaCO}_{3}$, in line with the 
Table 2. Product Selectivity (in \%) at $40 \%$ Conversion in the Hydrogenation of Various Nitroaromatic Compounds over the Catalysts $^{a}$

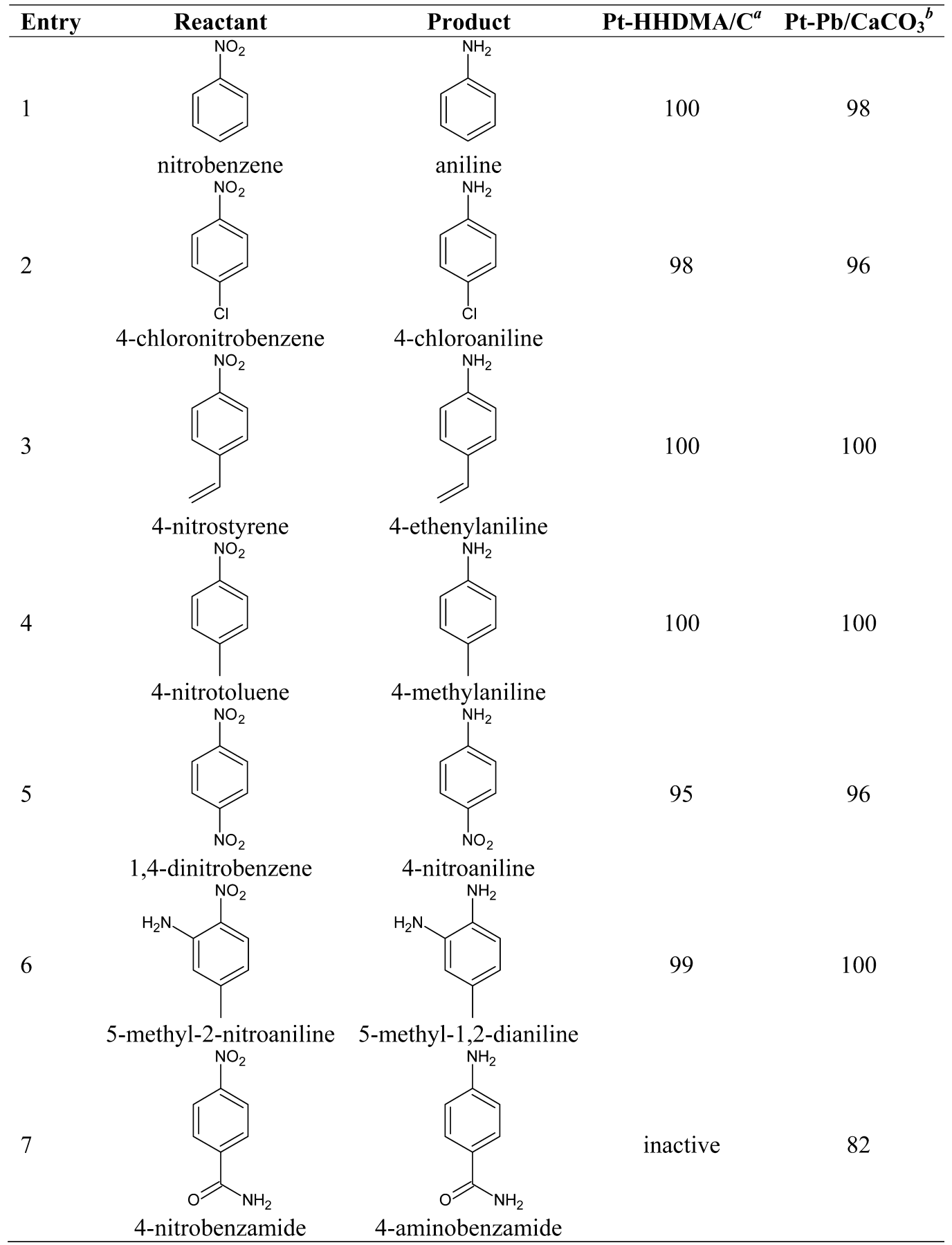

${ }^{a_{T}}=303 \mathrm{~K} .{ }^{b} \mathrm{~T}=363 \mathrm{~K}$. Other conditions: $P=1 \mathrm{bar}, F_{\mathrm{G}}\left(\mathrm{H}_{2}\right)=18 \mathrm{~cm}^{3} \mathrm{~min}^{-1}, F_{\mathrm{L}}($ nitroarene+THF $)=3 \mathrm{~cm}^{3} \mathrm{~min}^{-1}$.

literature reporting that the hydrogenation of simple aromatic nitroarenes poses few selectivity problems. ${ }^{7,10,17}$ In order to assess whether other catalysts can reach the same hydrogenation performance, we have tested $\mathrm{Pd}-\mathrm{Pb} / \mathrm{CaCO}_{3}, \mathrm{Pd}$ $\mathrm{HHDMA} / \mathrm{C}, \mathrm{Au} / \mathrm{TiO}_{2}$, and $\mathrm{Ag} / \mathrm{SiO}_{2}$ in the hydrogenation of nitrobenzene. All these catalysts yield incomplete conversions, which suggests that platinum is a suitable material for the sustainable manufacture of aniline derivatives in flow mode. The $\mathrm{Pt}-\mathrm{Pb} / \mathrm{CaCO}_{3}$ and Pt-HHDMA/C-catalyzed hydrogenation of chloronitrobenzene and nitrostyrene in Figure $7 \mathrm{~b}, \mathrm{c}$ follows a similar pattern as in the hydrogenation of the simplest nitroarene, with the colloidally prepared material being more active than $\mathrm{Pt}-\mathrm{Pb} / \mathrm{CaCO}_{3}$. On the other hand, both catalysts reach the same level of selectivity at comparable degree of conversion (Table 2, Entries $1-3$ ). In the past, $\mathrm{Pt}-\mathrm{Pb} / \mathrm{CaCO}_{3}$ proved to be one of the few systems that were able to selectively hydrogenate nitroarenes containing (multiple) unsaturations. The newly developed Pt-HHDMA catalyst matches the same level of aniline selectivity of $\mathrm{Pt}-\mathrm{Pb}$, with much lower $\mathrm{Pt}$ content and no $\mathrm{Pb}$.

The hydrogenation of 4-nitrotoluene (Entry 4) yields $45 \%$ conversion and $100 \%$ product selectivity over both catalysts. 

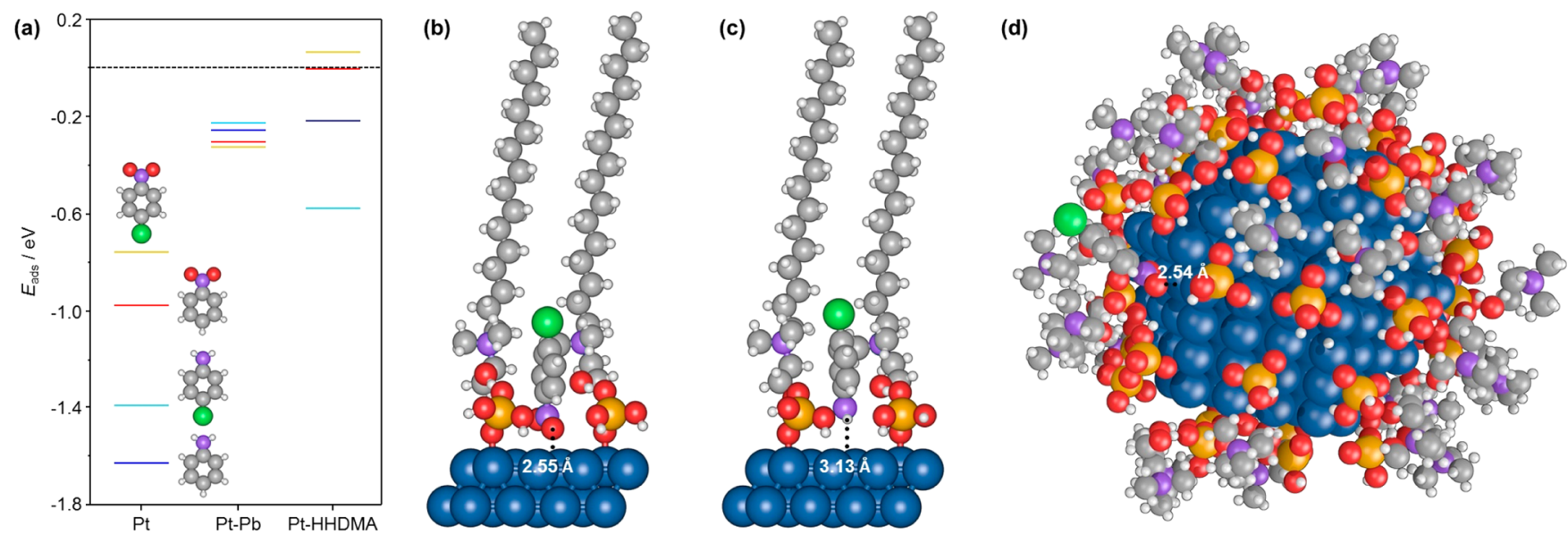

Figure 8. Adsorption energies of nitrobenzene (red), aniline (blue), 4-chloronitrobenzene (orange), and 4-chloroaniline (light blue) on Pt(111), $\mathrm{Pt}_{3} \mathrm{~Pb}(111)$, and $\mathrm{Pt}(111)$-HHDMA (a). DFT-calculated configuration for the adsorption of 4-chloronitrobenzene (b) and 4-chloroaniline (c) on $\mathrm{Pt}(111)$-HHDMA. Adsorption of 4-chloronitrobenzene on a ligand-coated $1.7 \mathrm{~nm}$ Pt model nanoparticle equilibrated with first-principles Molecular Dynamics (details in the Supporting Information) (d), providing a $-0.03 \mathrm{eV}$ adsorption energy. Color codes: $\mathrm{H}$ (white), C (light gray), $\mathrm{N}$ (purple), $\mathrm{O}$ (red), Cl (green), P (orange), and Pt (dark blue).

Applied in the partial hydrogenation of 1,4-dinitrobenzene and 2-5-methyl-2-nitroaniline (Entries 5 and 6), the Pt-HHDMA/C catalyst is highly selective to the corresponding aniline (95$99 \%)$ at $40 \%$ conversion. This result is similar to that of $\mathrm{Pt}-\mathrm{Pb}$ (96-100\% selectivity at ca. $40 \%$ conversion). As expected, the $\mathrm{Pb}$-poisoned catalyst shows an excellent degree of activity and selectivity in the hydrogenation of 4-nitrobenzamide (nearly $100 \%$ ), owing to the presence of lead, which strategically isolates the platinum sites. Comparatively, the ligand-modified catalyst is inactive in the reaction, likely due to the constraints created by the HHDMA ligand. Upon UV-ozone treatment of Pt-HHDMA for $5 \mathrm{~min}$, it is possible to partially remove part of the organic capping layer, without altering the platinum size, restoring the activity of the material at mild conditions $(21 \%$ conversion and $100 \%$ selectivity). However, much lower selectivities $(87 \%)$ were detected in the hydrogenation of 4nitrobenzamide over a fully cleaned Pt-based catalyst, pointing to the role of the ligand in orienting the reactants toward the $\mathrm{Pt}$ surface and preventing unselective reaction pathways. Notably, the outstanding degree of selectivity of the ligand-modified catalyst has been further confirmed in the solvent-free hydrogenation of nitrobenzene at $T=303 \mathrm{~K}, P=1$ bar, $F_{\mathrm{G}}\left(\mathrm{H}_{2}\right)=18 \mathrm{~cm}^{3} \mathrm{~min}^{-1}$, and $F_{\mathrm{L}}$ (nitroarene $\left.+\mathrm{THF}\right)=3 \mathrm{~cm}^{3}$ $\mathrm{min}^{-1}$, obtaining $100 \%$ aniline selectivity at $32 \%$ nitrobenzene conversion. Leaching of the active platinum species from the catalyst could also be excluded during hydrogenation. In fact, the liquid at the reactor outlet, containing the nitrobenzene, aniline, and tetrahydrofuran was fed to the reactor inlet (at $T=$ $293 \mathrm{~K}, P=20$ bar, $F_{\mathrm{G}}\left(\mathrm{H}_{2}\right)=18 \mathrm{~cm}^{3} \mathrm{~min}^{-1}, F_{\mathrm{L}}$ (substrate + solvent) $=0.3 \mathrm{~cm}^{3} \mathrm{~min}^{-1}$ ) using a cartridge filled only with silica, and no additional (homogeneous) hydrogenation occurred, evidencing no loss of the active phase.

4.3. Hydrogenation Mechanism. Thermodynamic Selectivity and Nitroarene Adsorption. The "thermodynamic selectivity" concept is the simplest descriptor that can be used to rationalize activity-selectivity patterns of challenging reactions such as the hydrogenation of functionalized nitroaromatics on platinum. This refers to the energy difference between the adsorption of the reactants and that of the products. ${ }^{39-41}$ A high thermodynamic selectivity demands that the reactants are much more strongly adsorbed than the products, which in turn desorb easily, without reduction of the remaining functionalities. The calculated adsorption energies of $\mathrm{C}_{6} \mathrm{H}_{5} \mathrm{NO}_{2}, \mathrm{ClC}_{6} \mathrm{H}_{4} \mathrm{NO}_{2}, \mathrm{C}_{6} \mathrm{H}_{5} \mathrm{NH}_{2}$, and $\mathrm{ClC}_{6} \mathrm{H}_{4} \mathrm{NH}_{2}$, and the relative optimized structures of the adsorbates on $\mathrm{Pt}(111)$, $\mathrm{Pt}_{3} \mathrm{~Pb}(111)$, and $\mathrm{Pt}(111)$-HHDMA are displayed in Figures 8a and S4. The target nitrobenzene and 4-chloronitrobenze molecules and the corresponding aniline species adsorb in a parallel configuration on the $\operatorname{Pt}(111)$ surface with a highly activated benzene ring sticking out of the surface. In particular, the products $\left(\mathrm{C}_{6} \mathrm{H}_{5} \mathrm{NH}_{2}\right.$ and $\left.\mathrm{ClC}_{6} \mathrm{H}_{4} \mathrm{NH}_{2}\right)$ adsorb stronger than the reactants $\left(E_{\mathrm{ads}}=-1.0 \mathrm{eV}\right.$ for nitroaromatics and ca. $-1.6 \mathrm{eV}$ for anilines). Therefore, the aniline derivatives can be overhydrogenated on $\mathrm{Pt}(111)$, resulting in a decreased product selectivity, or can remain on the surface, blocking part of the active sites. The high activation of the benzene ring and the strong chemisorption of the aniline species are behind the poor selectivity of clean $\mathrm{Pt}$ in the reduction of functionalized nitrocompounds.

On the $\mathrm{Pt}_{3} \mathrm{~Pb}$ stoichiometric surface representing the $\mathrm{Pb}$ poisoned catalyst, the target molecules adsorb in an almost flat configuration. The adsorption of $\mathrm{C}_{6} \mathrm{H}_{5} \mathrm{NO}_{2}$ and $\mathrm{ClC}_{6} \mathrm{H}_{4} \mathrm{NO}_{2}$ is moderately exothermic $\left(E_{\mathrm{ads}}=-0.25 \mathrm{eV}\right)$ and the interaction leading to the adsorption process is between the oxygen of the $-\mathrm{NO}_{2}$ group and the lead atoms of the surface. The reactants $\left(\mathrm{C}_{6} \mathrm{H}_{5} \mathrm{NO}_{2}\right.$ and $\left.\mathrm{ClC}_{6} \mathrm{H}_{4} \mathrm{NO}_{2}\right)$ are more strongly bonded to the surface than the products $\left(\mathrm{C}_{6} \mathrm{H}_{5} \mathrm{NH}_{2}\right.$ and $\left.\mathrm{ClC}_{6} \mathrm{H}_{4} \mathrm{NH}_{2}\right)$, although the benzene ring appears to be less activated than in the case of pure $\mathrm{Pt}$, in line with the higher selectivity found in the reduction of substituted nitroaromatics over $\mathrm{Pt}-\mathrm{Pb}$ catalysts (Table 2).

Much more complex is the adsorption of reactants on the PtHHDMA model surface. Our computed (111) facet presents a resting state that is very dense in HHDMA. Thus, the target molecules cannot be computationally fitted into the channels created by the ligands. In comparison, real nanoparticles are slightly less dense in surfactants (that is, there is a weaker packing energy of the tails), due to the concave effect of the curvature of the surface. Because of the very small size of PtHHDMA nanoparticles (ca. $2 \mathrm{~nm}$ ), there is a significant difference between the interface radius and the radius generated by the tail of the surfactant chain. Therefore, to keep the model 


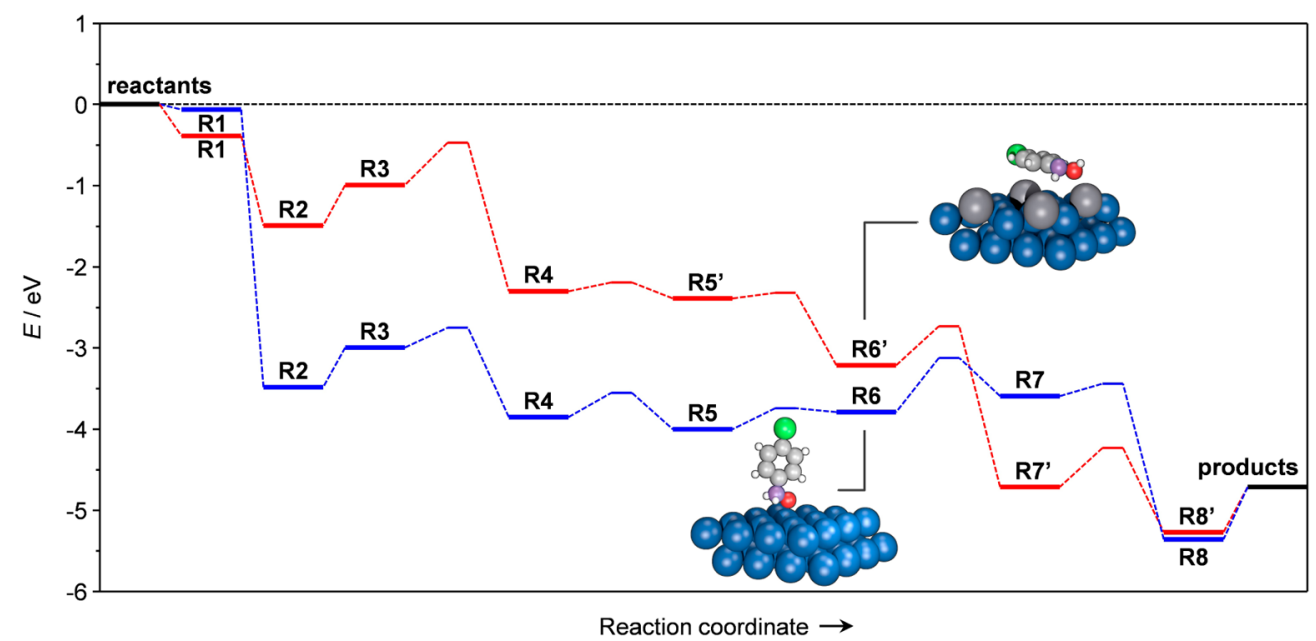

Figure 9. Energy profile for the hydrogenation of 4-chloronitrobenzene over $\mathrm{Pt}(111)$-HHDMA (blue) and $\mathrm{Pt}_{3} \mathrm{~Pb}(111)$ (red). The insets show the different states after addition of hydrogen to the nitroso compound over the $\mathrm{Pt}-\mathrm{Pb}$ (top) and Pt-HHDMA (bottom) surfaces. Color codes as specified in the caption of Figure 8 .

simple but meaningful, we have employed a Pt-HHDMA surface where an HHDMA- $\mathrm{H}_{2} \mathrm{PO}_{4}$ unit has been displaced. The energy cost for this step is about $0.15 \mathrm{eV}$. The adsorption of the target nitroaromatics occurs at this defect site on the surface. A vertical adsorption configuration with the benzene ring perpendicular to the surface and the $-\mathrm{NO}_{2}$ functionality pointing to the $\mathrm{Pt}$ is the preferred configuration. In particular, the distance between the $\mathrm{O}$ of the $-\mathrm{NO}_{2}$ group of 4chloronitrobenzene and the surface is $2.55 \AA$ (Figure $8 \mathrm{~b}$ ). This directionality is induced by the high coverage of the organic colloidal interphase and by the stabilizing interactions between the chains and the benzene rings. Although the adsorption strength of the reactants is weak $(-0.01$ and $+0.06 \mathrm{eV}$ for nitrobenzene and 4-chloronitrobenzene, respectively), it does correspond to a bound state. Thus, the process certainly occurs, in agreement with the hydrogenation activity, due to the hydrogen splitting ability of platinum and to the proximity of the $-\mathrm{NO}_{2}$ reducible group to the surface. Such perpendicular adsorption mode was reported in the past by Corma and coworkers to induce enhanced activity and selectivity in parasubstituted nitrobenzenes on $\mathrm{Au} / \mathrm{TiO}_{2}(110)$ model catalysts. ${ }^{42}$ As for the products, the interaction of aniline and 4chloroaniline on Pt-HHDMA is -0.22 and $-0.58 \mathrm{eV}$, respectively, and the distance between the $\mathrm{H}$ of the $-\mathrm{NH}_{2}$ group of 4-chloronitrobenzene and the surface is around $3.13 \AA$ (Figure 8c). This larger distance between the aniline species and the surface compared to the value computed for the respective nitro compound and the higher (less exothermic) adsorption energy of the products are in agreement with the high product selectivity of HHDMA-modified Pt-based catalysts.

An alternative adsorption mode with the $-\mathrm{Cl}$ functionality of the reactants and products in close proximity to the metal can also be inspected. In this case, the adsorption energy of $\mathrm{ClC}_{6} \mathrm{H}_{4} \mathrm{NO}_{2}$ and $\mathrm{ClC}_{6} \mathrm{H}_{4} \mathrm{NH}_{2}$ are -0.53 and $-0.50 \mathrm{eV}$, respectively. However, this configuration is not reactive because of the distance between the metal surface and the reducible $-\mathrm{NO}_{2}$ group (9.8 $\AA$ for 4-chloronitrobenzene and $9.7 \AA$ the 4chloroaniline).

Finally, in order to address the role of other model surfaces on the computed adsorption energies, we have modeled the adsorption of 4-chloronitrobenze on a $\mathrm{Pt}$ nanoparticle containing 260 atoms and coated with a ligand having phosphate and methylammonium groups (Figures $8 \mathrm{~d}$ and S5). The retrieved adsorption energy obtained for the coated nanoparticle differs by $0.1 \mathrm{eV}$ from that obtained on the (111) slab model employed in our calculations. This is below the accuracy of Density Functional Theory, strengthening our results, and is line with the convergence tests performed in the past by Nørskov and co-workers, ${ }^{43}$ showing stable adsorption energies for nanoparticles larger than $1.6 \mathrm{~nm}$.

Nitroarene Hydrogenation. The mechanism of hydrogenation of $\mathrm{ClC}_{6} \mathrm{H}_{4} \mathrm{NO}_{2}$ on $\mathrm{Pb}$ - and HHDMA-modified $\mathrm{Pt}$ has been studied by DFT. The reaction network below is based on the intermediates identified by Haber for the reduction of nitrobenzene in an electrochemical environment ${ }^{16}$ and takes into account the dissociative nature of $\mathrm{H}_{2}$ adsorption on $\mathrm{Ni}, \mathrm{Pd}$, or $\mathrm{Pt}{ }^{44}$

$$
\begin{aligned}
& \mathrm{ClC}_{6} \mathrm{H}_{4} \mathrm{NO}_{2}+* \rightleftharpoons \mathrm{ClC}_{6} \mathrm{H}_{4} \mathrm{NO}_{2} * \\
& \mathrm{H}_{2}+2^{*} \rightleftharpoons 2 \mathrm{H}^{*} \\
& \mathrm{ClC}_{6} \mathrm{H}_{4} \mathrm{NO}_{2}^{*}+\mathrm{H}^{*} \rightleftharpoons \mathrm{ClC}_{6} \mathrm{H}_{4} \mathrm{NOOH}^{*}+* \\
& \mathrm{ClC}_{6} \mathrm{H}_{4} \mathrm{NOOH}^{*}+\mathrm{H}^{*} \rightleftharpoons \mathrm{ClC}_{6} \mathrm{H}_{4} \mathrm{NO}^{*}+\mathrm{H}_{2} \mathrm{O}^{*} \\
& \mathrm{ClC}_{6} \mathrm{H}_{4} \mathrm{NO}^{*}+\mathrm{H}^{*} \rightleftharpoons \mathrm{ClC}_{6} \mathrm{H}_{4} \mathrm{NHO}^{*}+* \\
& \mathrm{ClC}_{6} \mathrm{H}_{4} \mathrm{NO}^{*}+\mathrm{H}^{*} \rightleftharpoons \mathrm{ClC}_{6} \mathrm{H}_{4} \mathrm{NOH}^{*}+* \\
& \mathrm{ClC}_{6} \mathrm{H}_{4} \mathrm{NHO}^{*}+\mathrm{H}^{*} \rightleftharpoons \mathrm{ClC}_{6} \mathrm{H}_{4} \mathrm{NH}_{2} \mathrm{O}^{*}+* \\
& \mathrm{ClC}_{6} \mathrm{H}_{4} \mathrm{NOH}^{*}+\mathrm{H}^{*} \rightleftharpoons \mathrm{ClC}_{6} \mathrm{H}_{4} \mathrm{NHOH}^{*}+* \\
& \mathrm{ClC}_{6} \mathrm{H}_{4} \mathrm{NH}_{2} \mathrm{O}^{*}+\mathrm{H}^{*} \rightleftharpoons \mathrm{ClC}_{6} \mathrm{H}_{4} \mathrm{NH}_{2} \mathrm{OH}^{*}+* \\
& \mathrm{ClC}_{6} \mathrm{H}_{4} \mathrm{NHOH}^{*}+\mathrm{H}^{*} \rightleftharpoons \mathrm{ClC}_{6} \mathrm{H}_{4} \mathrm{NH}_{2}^{*}+\mathrm{OH}^{*} \\
& \mathrm{ClC}_{6} \mathrm{H}_{4} \mathrm{NH}_{2} \mathrm{OH}^{*}+\mathrm{H}^{*} \rightleftharpoons \mathrm{ClC}_{6} \mathrm{H}_{4} \mathrm{NH}_{2}^{*}+\mathrm{H}_{2} \mathrm{O}^{*} \\
& \mathrm{OH}^{*}+\mathrm{H}^{*} \rightleftharpoons \mathrm{H}_{2} \mathrm{O}^{*}+* \\
& \mathrm{ClC}_{6} \mathrm{H}_{4} \mathrm{NH}_{2}^{*} \rightleftharpoons \mathrm{ClC}_{6} \mathrm{H}_{4} \mathrm{NH}_{2}+* \\
& \mathrm{H}_{2} \mathrm{O}^{*} \rightleftharpoons \mathrm{H}_{2} \mathrm{O}+*
\end{aligned}
$$


Considering the complexity of the reaction network involving several alternative steps (see Section 4 in the Supporting Information), it is not surprising that, in the last century, no other work has investigated the hydrogenation of nitroaromatic compounds with such a mechanistic depth. Figure 9 depicts the energy profiles for the hydrogenation of $\mathrm{ClC}_{6} \mathrm{H}_{4} \mathrm{NO}_{2}$ on representative surfaces of both catalysts, while all thermodynamic, kinetic, and geometric parameters as well as potential alternative steps are presented in the Supporting Information (Section 4) to enable readers reproduce the calculations. Over the $\mathrm{Pb}$-poisoned model system, $\mathrm{H}_{2}$ dissociates with a barrier of about $0.56 \mathrm{eV}$ with respect to the gas-phase reference, and the final state is exothermic by $0.57 \mathrm{eV}$ per $\mathrm{H}_{2}$ molecule (R2). Simultaneously, the chloronitrobenzene weakly adsorbs nearby. The first hydrogen addition to the nitro group forms an $\mathrm{R}-\mathrm{NOOH}$ group; this process is endothermic by $0.49 \mathrm{eV}(\mathrm{R} 3)$. The second hydrogen can reduce the formed intermediate in two potential positions: the R-NO and the R$\mathrm{NOH}$ fragment. This second possibility leads to the formation of a water molecule and is thermodynamic and kinetically preferred (R4). Similarly, the resulting nitrosobenzene can be hydrogenated in two different positions, $\mathrm{N}$ and $\mathrm{O}$. The hydrogenation of the $\mathrm{O}$ position is more likely to occur, leading to the $\mathrm{R}-\mathrm{NOH}$ intermediates $\left(\mathrm{R}^{\prime}\right)$. The subsequent hydrogenation yields phenylhydroxylamine $\left(\mathrm{R} 6^{\prime}\right)$, see the inset in the top part of Figure 9, which is quite stable on the surface (ca. 0.8 $\mathrm{eV}$ ) with respect to the previous intermediate, in agreement with the mechanistic proposal by Haber. ${ }^{16}$ A barrier of $0.55 \mathrm{eV}$ is found for the final hydrogenation step $\left(R 7^{\prime}\right)$, which consists in the hydrogenation of the $\mathrm{N}$ center and induces a $\mathrm{N}-\mathrm{OH}$ bond splitting $\left(\mathrm{R}^{\prime}\right)$ resulting in the aniline. Aniline desorption is endotermic by $0.23 \mathrm{eV}$ (R9). Water formation and desorption close the cycle and occur through low-energy steps. Overall, the catalyst appears to be selective but less active due to the large inhibiting nature of $\mathrm{H}_{2}$ dissociation and nitroarene adsorption on the $\mathrm{Pb}$-poisoned surface. Notice that the low adsorption energy of the nitro group would prevent the accumulation of large quantities of nitroarenes on the surface, reducing the possibility of the condensation path (Scheme 1) suggested by Haber. ${ }^{16}$

The major structural feature in the hydrogenation of 4chloronitrobenzene over the Pt-HHDMA model surface is the orientation of the nitrocompound, which adsorbs perpendicularly and with the $-\mathrm{NO}_{2}$ group directed toward the surface. Therefore, to describe the complex Pt-HHDMA system and investigate the consequences of the orientation change in the overall reactivity, we have considered a clean Pt surface where nitrobenzene adsorption occurs with this peculiar orientation. The ligand, in fact, acts as a spacer preventing bimolecular paths due to site isolation. The transfer of the first hydrogen species to $\mathrm{R}-\mathrm{NO}_{2}$ is endothermic by $0.49 \mathrm{eV}$ (R3). The resulting $\mathrm{R}-\mathrm{NOOH}$ intermediate can be hydrogenated to form a nitroso and a water molecule (R4); this process is exothermic and hindered by a small barrier $(0.24 \mathrm{eV})$. Differently from the $\mathrm{Pt}-\mathrm{Pb}$ catalyst, the subsequent $\mathrm{H}$ is transferred to the $\mathrm{N}$ atom, leading to an $\mathrm{R}-\mathrm{HNO}$ species; this process is thermoneutral and involves a barrier of only $0.30 \mathrm{eV}(\mathrm{R} 5)$. The hydrogenation of $\mathrm{R}-\mathrm{HNO}$ yields the formation of $\mathrm{R}-\mathrm{NH}_{2} \mathrm{O}$ (R6), see the inset in the bottom part of Figure 9. The reduction of $\mathrm{R}-$ $\mathrm{NH}_{2} \mathrm{O}$ is the most energy demanding step and form $\mathrm{R}-$ $\mathrm{NH}_{2} \mathrm{OH}$ (R7). This species is then reduced to obtain the aniline product and water, with an energy barrier of only 0.15
eV (R8). Product desorption is endothermic for both water and 4-chloroaniline.

The isolation of the active site created by the modifier (HHDMA or $\mathrm{Pb}$ ) explains the high selectivity observed over Pt-HHDMA and $\mathrm{Pt}-\mathrm{Pb}$ but not the much higher reactivity of the former. In the reaction profiles shown in Figure 9, all intermediates are below the zero reference and reactant or product removal from the surface is relatively easy. This is confirmed by classical Molecular Dynamics, showing that even for the capped Pt-HHDMA model, the diffusion of reactants and products along the HHDMA shell occurs in the range of picoseconds (see Figure S6 in the Supporting Information). Thus, the adsorption of molecular hydrogen appears to be a crucial step. On the Lindlar-type $\mathrm{Pt}-\mathrm{Pb}$ catalyst, $\mathrm{H}_{2}$ dissociation is rate-limiting, showing a remarkable energy barrier $(0.56 \mathrm{eV})$ due to ensemble effects (i.e., Pt is mainly surrounded by $\mathrm{Pb}$ atoms) on top of the entropic constraints related to the direct adsorption. ${ }^{29}$ Removing this bottleneck from the catalyst surface would ensure a higher reactivity. To evaluate the role of the ligand, $\mathrm{H}_{2}$ dissociation on a PtHHDMA-type model consisting of a platinum surface with the orthophosphate and capping $\mathrm{N}^{+}\left(\mathrm{CH}_{3}\right)_{3}\left(\mathrm{CH}_{2}\right) \mathrm{OH}$ moiety was investigated. On this system, $\mathrm{H}_{2}$ adsorption is weakly affected by the presence of the surfactant, since the DFT-calculated energy of adsorption $(-0.65 \mathrm{eV})$ is very close to that of $\mathrm{Pt}(111)(-0.77 \mathrm{eV})$. Besides, this step is enthalpically barrierless on the Pt-HHDMA model, as in the case of Pt. This nicely explains the higher activity of Pt-HHDMA in comparison with $\mathrm{Pt}-\mathrm{Pb}$ (Table 2 and Figure 7).

\section{CONCLUSIONS}

We have employed a battery of complementary methods to characterize the materials, performed catalytic evaluations in continuous mode, and conducted pioneering computational studies to advance the understanding of the state-of-the-art ligand-modified Pt-based catalyst for nitroarene hydrogenation, whose activity largely surpasses those of all catalytic systems reported in the last two decades. Our research program targeted fundamental questions about the nature and reactivity of the inorganic-organic interface in the hybrid system, in comparison to the industrially relevant $\mathrm{Pt}-\mathrm{Pb}$ catalyst. In particular, it was possible to trace back the activity and selectivity of these catalytic materials to geometric and electronic contributions derived from the experimental and theoretical work. Differently from the $\mathrm{Pt}-\mathrm{Pb}$ sample, in which lead strategically substitutes the Pt species on the nanoparticle surface, the colloidally prepared Pt-HHDMA catalyst presents a three-dimensional architecture where the hydrogen phosphate anions of the ligand preferentially adsorb on the Pt surface with the cationic surfactant heads bridging different positions. As depicted by the classical MD simulations, the reactants pass across the ligand shell to reach the active sites. Kinetic tests conducted in a flow microreactor have demonstrated the superior activity of $\mathrm{Pt}-\mathrm{HHDMA} / \mathrm{C}$ with respect to the benchmark $\mathrm{Pt}-\mathrm{Pb} / \mathrm{CaCO}_{3}$ for a wide array of nitroaromatics containing halogen, carbonyl, olefinic, and nitrile functionalities. The high selectivity of both materials has been ascribed to geometric effects (i.e., to the perpendicular adsorption mode of the reactants), which prevents unselective reaction pathways such by inducing site isolation. As for the activity, the organic ligand in Pt-HHDMA prevents the electronic poisoning of the $\mathrm{Pt}$ sites (present in $\mathrm{Pt}-\mathrm{Pb}$ ) and alleviates the energy penalty required for the activation of molecular hydrogen. Additionally, 
we have presented the first complete computational analysis of the century-old Haber mechanism for nitroarene reduction. These findings substantially enrich the structural and mechanistic understanding of HHDMA-modified catalysts, offering a wide perspective for the advanced design of hybrid nanocatalysts for challenging reactions.

\section{ASSOCIATED CONTENT}

\section{S Supporting Information}

The Supporting Information is available free of charge on the ACS Publications website at DOI: 10.1021/acscatal.5b00885.

Additional characterization data of the catalysts, structural models, and DFT calculations for the adsorption and hydrogenation steps (PDF)

\section{AUTHOR INFORMATION}

\section{Corresponding Authors}

*E-mail: nlopez@iciq.es (N.L.).

*E-mail: jpr@chem.ethz.ch (J.P.R.).

\section{Notes}

The authors declare no competing financial interest.

\section{ACKNOWLEDGMENTS}

Financial support from ETH Zurich, the Spanish Ministerio de Economía y Competitividad (CTQ2012-33826 (N.L.) and "Ayuda formación Posdoctoral" Fellowship (N.A-B.)), and the ICIQ Foundation is acknowledged. We thank Dr. Frank Krumeich, Dr. Laetitia Bernard, Dr. René Verel, and Dr. Roland Hauert for their help with electron microscopy, ToF-SIMS, ${ }^{31} \mathrm{P}$ NMR, and XPS analyses. The FIRST Laboratory and the Scientific Center for Optical and Electron Microscopy (ScopeM) at ETH Zurich are thanked for providing access to their facilities. The Micromeritics Instrument Grant Program is gratefully acknowledged. BSC-RES is acknowledged for the generous computational resources.

\section{REFERENCES}

(1) Xia, Y.; Yang, H.; Campbell, C. T. Acc. Chem. Res. 2013, 46, $1671-1672$.

(2) Antonietti, M.; Kuang, D.; Smarsly, B.; Zhou, Y. Angew. Chem., Int. Ed. 2004, 43, 4988-4992.

(3) Cozzoli, P. D.; Pellegrino, T.; Manna, L. Chem. Soc. Rev. 2006, 35, $1195-1208$.

(4) An, K.; Somorjai, G. A. Chem CatChem 2012, 4, 1512-1524.

(5) Roucoux, A.; Schulz, J.; Patin, H. Chem. Rev. 2002, 102, 37573778 .

(6) Witte, P. T.; de Groen, M.; de Rooij, R. M.; Bakermans, P.; Donkervoort, H. G.; Berben, P. H.; Geus, J. W. Stud. Surf. Sci. Catal. 2010, 175, 135-143.

(7) Boymans, E.; Boland, S.; Witte, P. T.; Müller, C.; Vogt, D. ChemCatChem 2013, 5, 431-434.

(8) Vilé, G.; Almora-Barrios, N.; Mitchell, S.; López, N.; PérezRamírez, J. Chem. - Eur. J. 2014, 20, 5926-5937.

(9) Tafesh, A. M.; Weiguny, J. Chem. Rev. 1996, 96, 2035-2052.

(10) Blaser, H.-U.; Steiner, J.; Studer, M. ChemCatChem 2009, 1, 210-221.

(11) Roberge, D. M.; Ducry, L.; Bieler, N.; Cretton, P.; Zimmermann, B. Chem. Eng. Technol. 2005, 28, 318-323.

(12) Lara, P.; Philippot, K. Catal. Sci. Technol. 2014, 4, 2445-2465.

(13) de Mas, N.; Gunther, A.; Jensen, M. A. Ind. Eng. Chem. Res. 2003, 42, 698-710.

(14) Wegner, J.; Ceylan, S.; Kirschning, A. Chem. Commun. 2011, 47, 4583-4592.
(15) Hessel, V.; Vural-Gursel, I.; Wang, Q.; Noël, T.; Lang, J. Chem. Eng. Technol. 2012, 35, 1184-1204.

(16) Leipzig, B. Z. Elektrochem. Angew. Phys. Chem. 1898, 4, 506514.

(17) Siegrist, U.; Baumeister, P.; Blaser, H. U.; Studer, M. In Catalysis of Organic Reactions; Herkes, F. E., Ed.; Marcel Dekker: New York, 1998, Vol. 75, pp 207-219.

(18) Perrichon, V.; Retailleau, L.; Bazin, P.; Daturi, M.; Lavalley, J. C. Appl. Catal., A 2004, 260, 1-8.

(19) Satterfield, C. N. AIChE J. 1975, 21, 209-228.

(20) Kresse, G.; Furthmuller, J. Phys. Rev. B: Condens. Matter Mater. Phys. 1996, 54, 11169-11186.

(21) Kresse, G.; Furthmuller, J. Comput. Mater. Sci. 1996, 6, 15-50.

(22) Hammer, B.; Hansen, L. B.; Nørskov, J. K. Phys. Rev. B: Condens. Matter Mater. Phys. 1999, 59, 7413-7421.

(23) Grimme, S. J. Comput. Chem. 2006, 27, 1787-1799.

(24) Bucko, T.; Hafner, J.; Lebegue, S.; Angyan, J. G. J. Phys. Chem. A 2010, 114, 11814-11824.

(25) Almora-Barrios, N.; Carchini, G.; Błoński, P.; López, N. J. Chem. Theory Comput. 2014, 10, 5002-5009.

(26) Kresse, G.; Joubert, D. Phys. Rev. B: Condens. Matter Mater. Phys. 1999, 59, 1758-1775.

(27) Price, S. W. T.; Ignatyev, K.; Geraki, K.; Basham, M.; Filik, J.; Vo, N. T.; Witte, P. T.; Beale, A. M.; Mosselmans, J. F. W. Phys. Chem. Chem. Phys. 2015, 17, 521-529.

(28) Chadwick, D.; Karolewski, M. A. Surf. Sci. 1983, 126, 41-48.

(29) García-Mota, M.; Gómez-Díaz, J.; Novell-Leruth, G.; VargasFuentes, C.; Bellarosa, L.; Bridier, B.; Pérez-Ramírez, J.; López, N. Theor. Chem. Acc. 2011, 128, 663-673.

(30) Henkelman, G.; Uberuaga, B. P.; Jónsson, H. J. Chem. Phys. 2000, 113, 9901-9904.

(31) Porsgaard, S.; Merte, L. R.; Ono, L. K.; Behafarid, F.; Matos, J.; Helveg, S.; Salmeron, M.; Roldàn Cuenya, B.; Besenbacher, F. ACS Nano 2012, 6, 10743-10749.

(32) Matolín, V.; Cabala, M.; Matolínová, I.; Škoda, M.; Václavū, M.; Prince, K. C.; Skála, T.; Mori, T.; Yoshikawa, H.; Yamashita, Y.; Ueda, S.; Kobayashi, K. Fuel Cells 2010, 10, 139-144.

(33) Ismagilov, Z. R.; Yashnik, S. A.; Startsev, A. N.; Boronin, A. I.; Stadnichenko, A. I.; Kriventsov, V. V.; Kasztelan, S.; Guillaume, D.; Makkee, M.; Moulijn, J. A. Catal. Today 2009, 144, 235-250.

(34) Xia, F.; Rudack, T.; Cui, Q.; Kötting, C.; Gerwert, K. J. Am. Chem. Soc. 2012, 134, 20041-20044.

(35) Witte, P. T.; Boland, S.; Kirby, F.; van Maanen, R.; Bleeker, B. F.; de Winter, M.; Post, J. A.; Geus, J. W.; Berben, P. H. ChemCatChem 2013, 5, 582-587.

(36) Weng, L. T. Appl. Catal., A 2014, 474, 203-210.

(37) Liu, X.; Yu, M.; Kim, H.; Mameli, M.; Stellacci, F. Nat. Commun. 2012, 3, 1182.

(38) Magnussen, O. M. Chem. Rev. 2002, 102, 679-725.

(39) Segura, Y.; López, N.; Pérez-Ramírez, J. J. Catal. 2007, 247, 383-386.

(40) Studt, F.; Abild-Pedersen, F.; Bligaard, T.; Sørensen, R. Z.; Christensen, C. H.; Nørskov, J. K. Science 2008, 320, 1320-1322.

(41) Vilé, G.; Baudouin, D.; Remediakis, I. N.; Copéret, C.; López, N.; Pérez-Ramírez, J. ChemCatChem 2013, 5, 3750-3759.

(42) Boronat, M.; Concepción, P.; Corma, A.; González, S.; Illas, F.; Serna, P. J. Am. Chem. Soc. 2007, 129, 16230-16237.

(43) Li, L.; Larsen, A. H.; Romero, N.; Morozov, V. A.; Glinsvad, C.; Abild-Pedersen, F.; Greeley, J.; Jacobsen, K.; Nørskov, J. K. J. Phys. Chem. Lett. 2013, 4, 222-226.

(44) Horiuti, J.; Polanyi, M. Trans. Faraday Soc. 1934, 30, 11641172. 